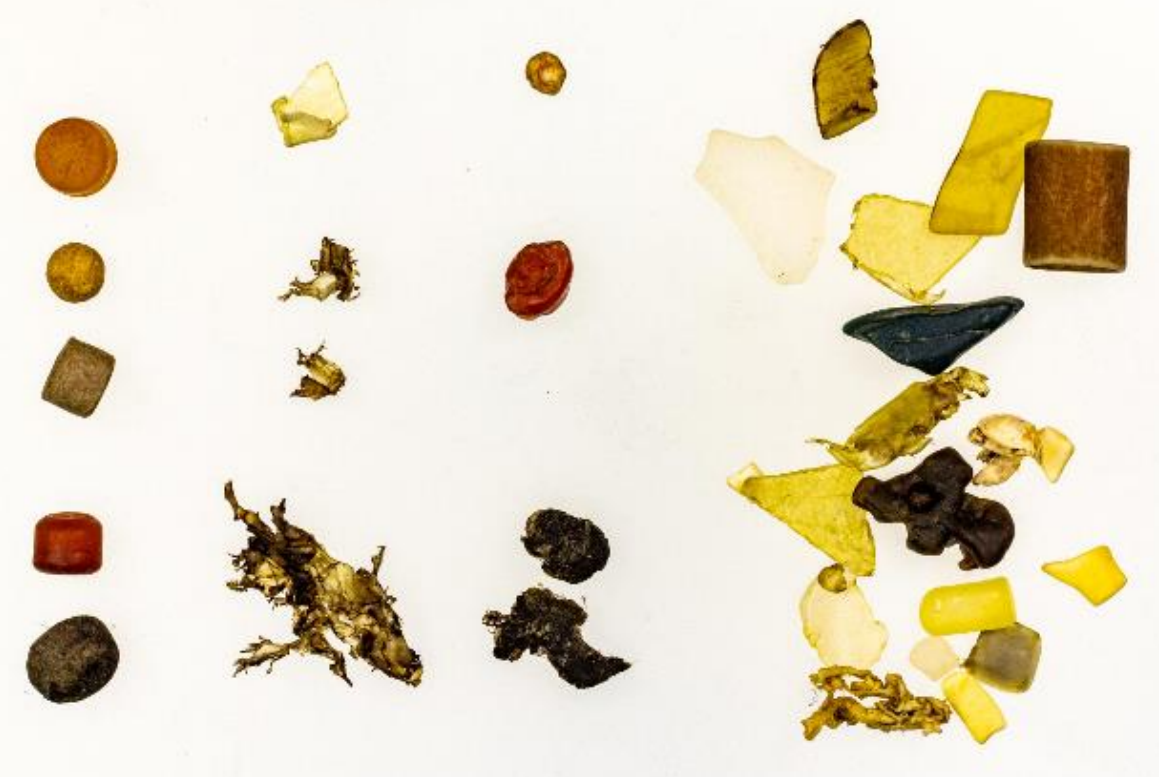

\title{
SNS Fulmar Study Report SKAGERRAK 2002-21
}

Jan A. van Franeker, Susanne Kühn, André Meijboom \& Oliver Bittner 


\section{Abstract}

This document is an illustrated report for the surveyors in the monitoring program of plastics particles in stomachs of beached northern fulmars (Fulmarus glacialis) in the north of Denmark and the south of Norway. It contains a report on 20 years of data collected since the start of the Save the North Sea (SNS) project in 2002 until about July 2021. As an illustration of the current situation photos are provided of stomach contents of all individual birds over the recent 5-year period 2017-2021. Data indicate a decrease in plastic mass in the Skagerrak since 2002, but the pattern is statistically insignificant. However, such data do contribute to the statistically significant decrease recently calculated for the total of the North Sea. Lower sample sizes within a specific area or period are not a major problem in the larger monitoring program.

\section{Citation}

Van Franeker, J.A., Kühn, S., Meijboom, A. \& Bittner, O. (2021).

SNS Fulmar Study Report - SKAGERRAK 2002-21.

Wageningen Marine Research, Den Helder, 30pp.

Doi $\quad$ https://doi.org/10.18174/556442

WUR Edepot https://edepot.wur.nl/556442

\section{Contact}

Susanne Kühn

Wageningen Marine Research, Ankerpark 27, 1781 AG Den Helder, The Netherlands

E: $\quad$ Susanne.kuehn@wur.nl

M: $\quad+31621992568$

W: $\quad$ www.wur.eu/plastics-fulmars

All photos by the first author.

(C) Wageningen Marine Research

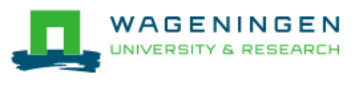

(C2021 Wageningen Marine Research. This work is licensed under the Creative Commons CC-BY-NC-SA license. For license conditions see: https://creativecommons.org/licenses/by-nc-sa/4.0/legalcode

Wageningen Marine Research accepts no liability for consequential damage, nor for damage resulting from applications of the results of work or other data obtained from Wageningen Marine Research. Client indemnifies Wageningen Marine Research from claims of third parties in connection with this application. 


\section{SNS Fulmar Study Report SKAGERRAK 2002-21}

\section{Introduction}

Since 2002, stomach contents of beached fulmars from around the North Sea are studied for the amount of ingested plastic. The start of this work was supported by the European Interreg project for the North Sea 2002-2004. The fulmar study was part of the Save the North Sea (SNS) program that intended to reduce marine litter through increased awareness.

Even if the formal EU supported SNS program lasted for only three years, the fulmar group has continued to run the monitoring program, which was only possible thanks to the support given by so many volunteers. Nowadays, this monitoring project is a formal governmental monitoring project in OSPAR (Convention for the Protection of the Marine Environment of the North-East Atlantic) and in the European Union's MSFD (Marine Strategy Framework Directive). The long-term target set by these authorities is that the proportion of fulmars with more than 0.1 gram of plastic in the stomach should be reduced to under $10 \%$ for a period of at least five years in samples of at least 100 birds. In OSPAR this was called the 'Ecological Quality Objective (EcoQO), which in EU terms is replaced by 'Fulmar Threshold Value' (Fulmar-TV or FTV). Current levels are substantially above the $10 \%$, meaning that authorities have a commitment of making further efforts to reduce marine litter until reaching the EcoQO or FTV.

Monitoring efforts are national commitments, but Fulmars do not live in countries, they roam over our marine waters without national borders. The Skagerrak is a natural marine entity that seasonally attracts many seabirds, including fulmars. As a special thanks to all volunteers in northern Denmark (Skagen) and southern Norway (Lista) (Figure 1), we decided to dedicate a short special report integrating 20 years of data from the Skagerrak area. One of the reasons to write this report is that in September 2021, the Danish government has granted the fulmar monitoring project to another organisation, so for the Danish monitoring, this is our concluding report to the volunteers.

In addition to the longer term monitoring results (2002-2021), this report provides, for the recent 5-year period 2017-2021, a separate photo-info page of stomach content from each individual bird. Photo-info pages include birds that lacked a stomach (taken out by scavengers) or that had a stomach but without any plastic, in order to illustrate our complete results. 


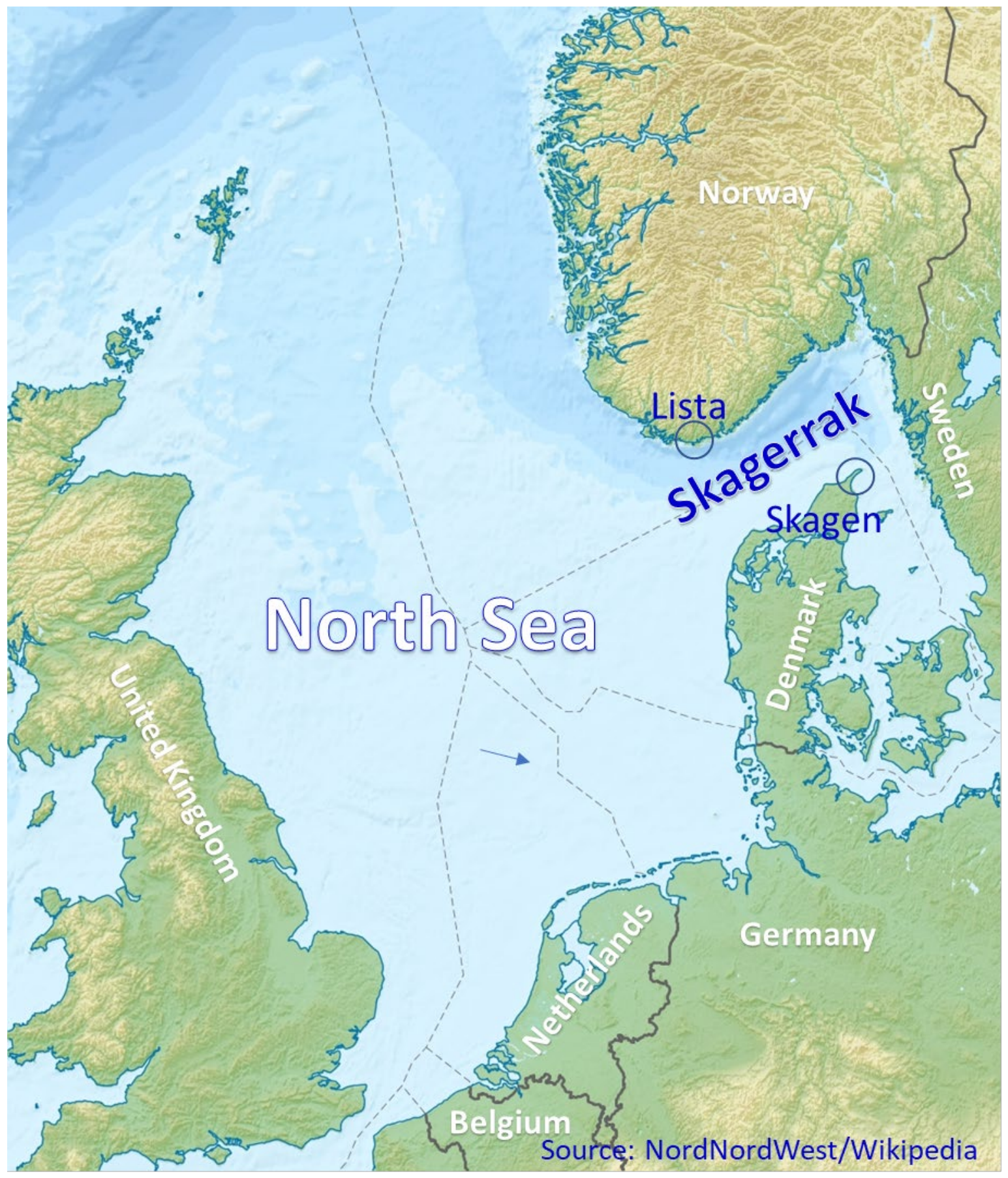

Figure 1 Map of the North Sea, showing the Skagerrak between Norway, Denmark and Sweden, with its main sampling locations of beached fulmars in Lista and Skagen. 


\section{Methods}

Methods and associated literature references are described in detail in our recent publication on overall North Sea data 2002-2018 (https://doi.org/10.1016/.jmarpolbul.2021.112246) and need not to be fully repeated here.

In short: the monitoring program uses beached fulmars (Photo 1), collected by local volunteers. It has been shown that stomach contents of these beached birds are not statistically different from the stomach contents from live fulmars, so data are representative for all fulmars out at sea. In Lista Norway the survey network has been organised by Kåre Olav Olsen of the 'Norsk Ornitologisk Forening Lister Lokallag'. In Denmark this was done by John Pedersen and Poul Lindhard Hansen. At opportunity basis the bird corpses were picked up by the researchers of Wageningen Marine Research. Volunteers are specifically asked to collect also older, decaying, smelly corpses, as long as the stomach may be present. It is preferred to occasionally receive birds that prove to have no or an incomplete stomach, rather than missing any valuable birds. In order to promote the collection of old and smelly corpses, we have placed a message on our dossier www.wur.eu/plastics-fulmars (message of 15 April 2021) that contains a short video on how to collect a dirty bird with clean hands. The short video is also available on YouTube www.youtube.com/watch?v=QvzadnYkapM

Dissections are either done locally during pickup, or later in the labs in the Netherlands. During necropsies, issues like morphology, moult, age, sex, potential cause of death, body condition etc. are assessed. Stomach contents are rinsed with cold water over a sieve mesh of $1.0 \mathrm{~mm}$. Smaller sizes are relatively rare because they pass into the intestines and are excreted. Contents are categorized in different (sub-)categories of plastic and other litter. These are counted for number of particles and weighed with an accuracy to the $4^{\text {th }}$ decimal of a gram. Most abbreviations used in the photo-pages are fairly self-evident or directly explained. However, the acronyms for cause of death are sometimes less straightforward and are explained in the supplementary pages at the end of this document. Results are expressed as

- Frequency of Occurrence (\%FO) showing the proportion of birds that contained any plastic

- Average number of particles and mass of plastics with standard-error of the means. These are 'population averages' meaning that birds without any plastic are included in the calculated averages

- Proportion of birds with more than $0.1 \mathrm{~g}$ of plastic in the stomach (EcoQ\% or FTV\%) 
Main categories are for industrial plastic pellets, the raw material for plastic processing industries, and user plastics, for all types of plastic consumer waste. For statistical tests of trends over years, or differences between groups, we refer to our recent North Sea publication.

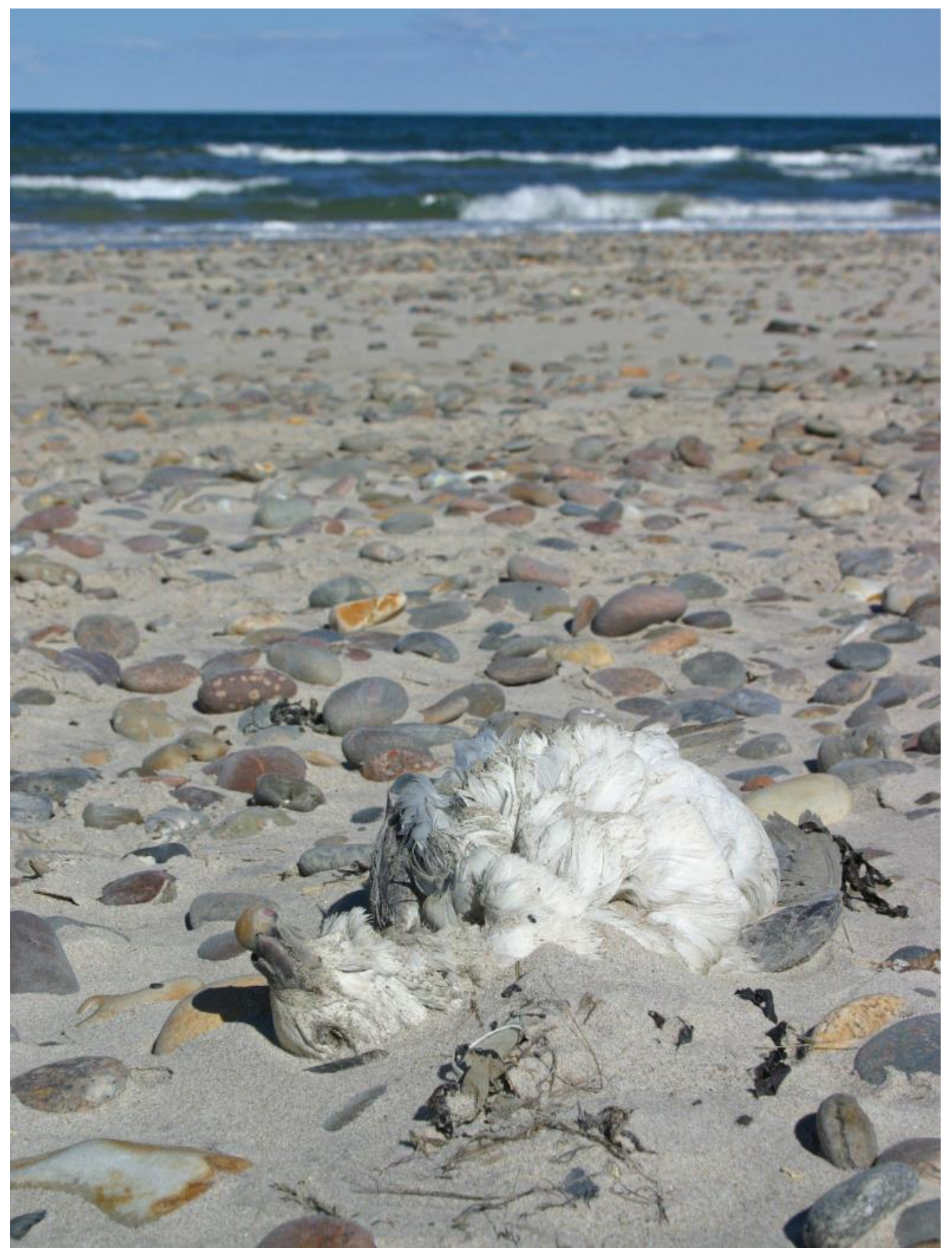

Photo 1

Fulmar found on the beach of Skagen in the early phase of the Save the North Sea project (7 April 2003). Gradually over the years, less fulmars have beached, a phenomenon observed on many of the North Sea coastlines. 


\section{Monitoring Results and discussion}

Overall 287 fulmars have been collected in the Skagerrak area, of which 99 near Lista in Norway, and 188 near Skagen in Denmark. The majority of these were collected in the early years of the SNS project, as in recent years less fulmars have been found on the coastlines of many countries.

As a standard in the fulmar monitoring program, data for the past five years are considered as the 'current situation' to compare with the policy targets. Unfortunately in recent years not many fulmars were found on the beaches, a phenomenon observed on more coasts of the North Sea. Because of the small samples over the 2017-2021 period, the differences in averages between Lista and Skagen as suggested in Table 1 are statistically completely insignificant and may be accidental (e.g. for plastic mass Mann Whitney $U$ test $\mathrm{U}=160 \mathrm{p}=0.438$ ). The same applies to the EcoQO \% for the proportion of birds having more than 0.1 gram of plastic. The combined Skagerrak EcoQ\% of $29 \%$ seems low but is still significantly higher than the policy target of $10 \%(z=2.1 ; p=0.032)$ but the test indicates that the small sample size of only 14 birds should be considered inappropriate.

Table $1 \quad$ Plastics in stomachs of fulmars from around Lista in Norway and Skagen in Denmark, separate by location and combined for the Skagerrak. The 2017-2021 period is relevant for evaluations of meeting the policy target, but is low on sample sizes. The long term 2002-2021 data show near identical results for the Danish and Norwegian birds, indicating that both can be combined as a representative figure for the Skagerrak marine waters. \%FO = Frequency of Occurrence; EcoQ\%=proportion of birds with more than $0.1 \mathrm{~g}$ of plastic; geometric mean is based on log transformed data to reduce influence of outliers.

\begin{tabular}{|c|c|c|c|c|c|c|c|c|c|c|c|c|}
\hline \multirow[b]{2}{*}{ Area and period } & \multirow[b]{2}{*}{ stomachs } & \multicolumn{3}{|c|}{ INDUSTIAL } & \multicolumn{3}{|c|}{ USER } & \multicolumn{5}{|c|}{ ALL PLASTICS } \\
\hline & & $\%$ FO & $\mathbf{n}$ & mass & $\%$ FO & n & mass & $\%$ FO & $\mathbf{n}$ & mass & $\begin{array}{r}\text { Geometric } \\
\text { mean mass }\end{array}$ & $\begin{array}{c}\text { EcoQ } \% \\
\text { (over } 0.1 \mathrm{~g}) \\
\end{array}$ \\
\hline Lista 2017-21 & 5 & $40 \%$ & 1.2 & 0.02 & $100 \%$ & 11.2 & $\overline{0.06}$ & $100 \%$ & 12.4 & 0.08 & 0.03 & $20 \%$ \\
\hline Skagen 2017-21 & 9 & $56 \%$ & 1.2 & 0.02 & $100 \%$ & 23.7 & 0.10 & $100 \%$ & 24.9 & 0.12 & 0.06 & $33 \%$ \\
\hline Skagerrak 2017-21 & 14 & $50 \%$ & 1.2 & 0.02 & $100 \%$ & 19.2 & 0.09 & $100 \%$ & 20.4 & 0.11 & 0.05 & $29 \%$ \\
\hline Lista 2002-21 & 99 & $53 \%$ & 3.6 & 0.07 & $98 \%$ & 37.4 & 0.24 & $98 \%$ & 40.9 & 0.31 & 0.09 & $52 \%$ \\
\hline Skagen 2002-21 & 188 & $56 \%$ & 2.5 & 0.05 & $93 \%$ & 37.9 & 0.25 & $93 \%$ & 40.4 & 0.30 & 0.07 & $48 \%$ \\
\hline Skagerrak 2002-21 & 287 & $55 \%$ & 2.9 & 0.06 & $95 \%$ & 37.7 & 0.25 & $95 \%$ & 40.6 & 0.30 & 0.08 & $49 \%$ \\
\hline
\end{tabular}

When considering the longer term, the 20 year time series 2002-2021 (Table 1), the overall plastic numbers and masses in Skagen and Lista fulmars were very similar. For number of particles, Skagen fulmars averaged with standard error at $40.4 \pm 8.1$ and the figure for Lista was $40.9 \pm 8.0$. Maximum number for an individual stomach was 1123 particles in Skagen, and 457 in Lista. Average mass of plastic in stomachs of Skagen birds was $0.30 \pm 0.11$ gram, and the average for Lista was $0.31 \pm 0.05$ gram. Maximum mass in an 
individual stomach from Skagen was $20.5691 \mathrm{gram}$, and from Lista $1.9090 \mathrm{gram}$. The fulmar with 20.5691 gram of plastic is the 'champion' in the whole of the SNS fulmar data set (Photo 1). To reduce the impact of such extremes, Table 1 not only shows the arithmetic averages for numbers and mass, but also the geometric mean mass (calculated from logarithm transformed data reducing the impact of outliers). Overall for 287 Skagerrak fulmars $49 \%$ of the birds had more than 0.1 gram of plastic in the stomach, which is significantly higher than the policy target of $10 \%(Z=8.6 ; p<0.001)$.

Detailed tables with Skagerrak data for all 5-year periods are provided at the end of this report.

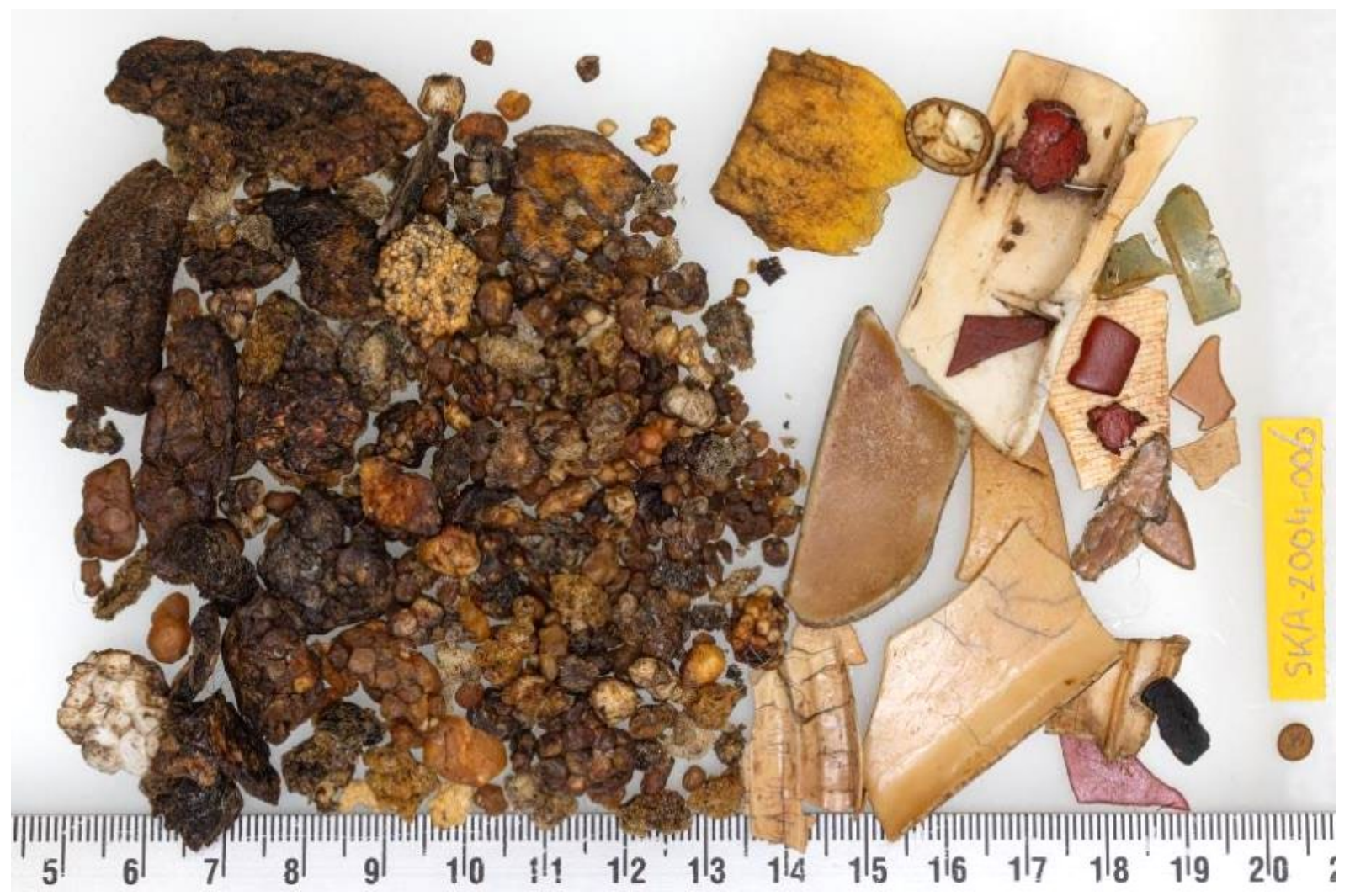

Photo 2 Plastics in stomach of Fulmar SKA-2004-006. With an overall mass of $20.6 \mathrm{gram}$ of plastics, this fulmar had the most extreme stomach content found in the Save the North Sea fulmar study. Contents were mainly polystyrene foam and large hard fragments, with only a single industrial granule. The scale bar is in $\mathrm{cm}$, subdivided in $\mathrm{mm}$.

Comparing the current 5-year data 2017-2021 with the long term data 2002-2021 in Table 1 shows that the recent data are relatively low compared to the long term average. The difference is almost a factor three. The smaller difference between the geometric means indicates that this may be caused by more extreme outliers in the early years of the project.

The pattern seen in a graph of running 5 year averages for ingested plastic mass (Figure 2) suggest a gradual decrease, so an improvement of the environmental conditions for marine litter in the Skagerrak area. Not included in this dataset is a small sample of six fulmars from the Swedish Skagerrak coast collected in 2003: with an average plastic mass of 
$0.63 \mathrm{~g}$ this sample would have heightened the first two datapoints in Figure 2, enforcing the observed trend. However, no fulmars were collected by Sweden in later years, so inclusion of the single sample could bias the trendline. Unfortunately, available sample sizes from the Skagerrak have gradually decreased since the early years. Using our standard test for trends (linear regression of log transformed plastic mass for all individual birds against the year of collection), the downward slope is not statistically significant (long term period 2002-21 $n=287 p=0.36$; standard 10-year period 2012-2021 $n=45 p=0.49$ ). However, the Skagerrak data certainly contribute to statistically valid patterns when using the larger sample sizes from the combined monitoring programs around the North Sea. Over the 10-year period 2009 to 2018 , combined data from fulmar stomachs from all around the North Sea, showed downward slopes for all subregions, which together evidenced a significant downward trend $(n=1117 ; p=0.011)$

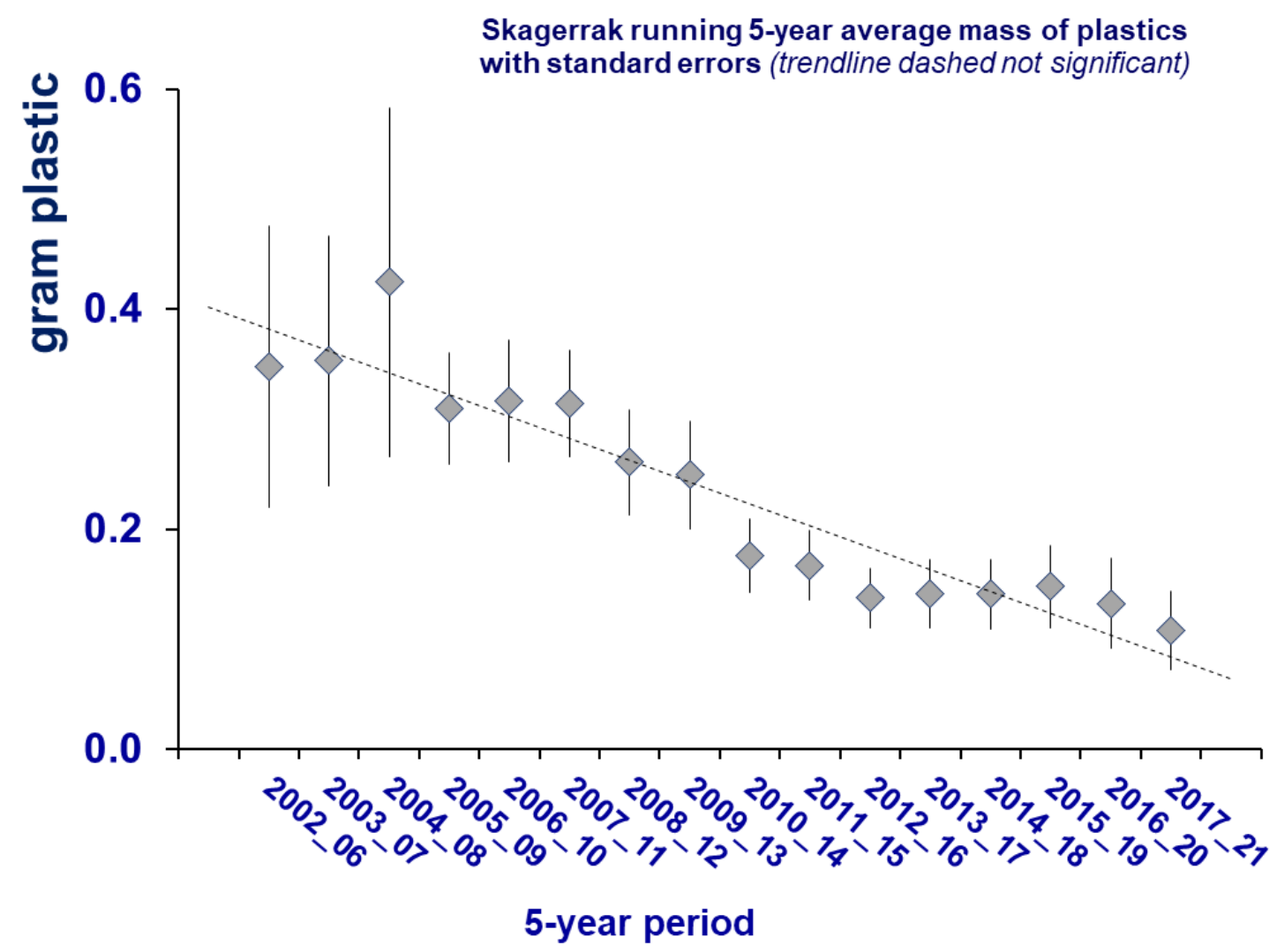

Figure 2 Running 5-year average values for plastic mass in the stomachs of fulmars from the Skagerrak area. Data suggest a decrease in ingested plastic mass, but in a statistical sense there is no significant trend.

In data for the North Sea as a whole, it could also be shown that in addition to the changes over the years, younger birds tended to have more plastics in the stomachs than 
adults, and probably females more than males. Such differences could not be shown in the Skagerrak material.

The above data are for the combination of industrial plastic granules and the user plastics, that is the consumer debris items in the fulmar stomachs. The downward slope can be seen for both plastic categories in Figure 3. There was a remarkable drop in industrial plastic mass during the recent 5-year period.

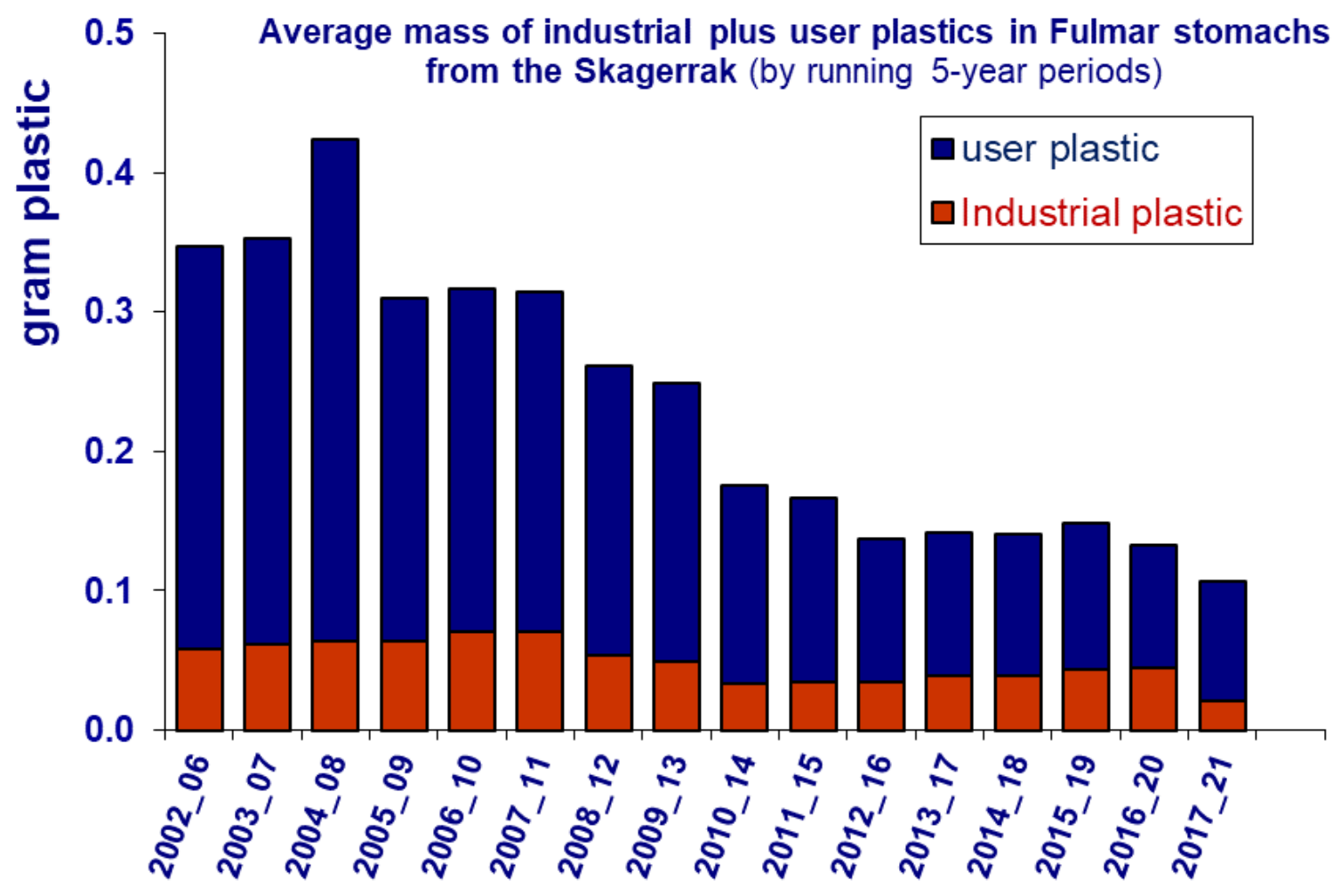

Figure $3 \quad$ Running 5-year average values for cumulative plastic mass in the stomachs of fulmars from the Skagerrak area, split in the categories of industrial pellets and user plastics (consumer wastes).

In policy terms, the important result to look at concerns the EcoQ Performance or EcoQ\%, that is the proportion of stomachs containing more than 0.1 gram of plastic. Results in Figure 4 do not show the downward pattern observed in plastic mass (Figures 2 and 3), except for the last two five year periods for data since 2016, but the sample sizes are small. However, it is evident that the EcoQ\% for the Skagerrak is far above that of the $10 \%$ policy target, throughout all years of monitoring. The same is true for the wider North Sea area. 


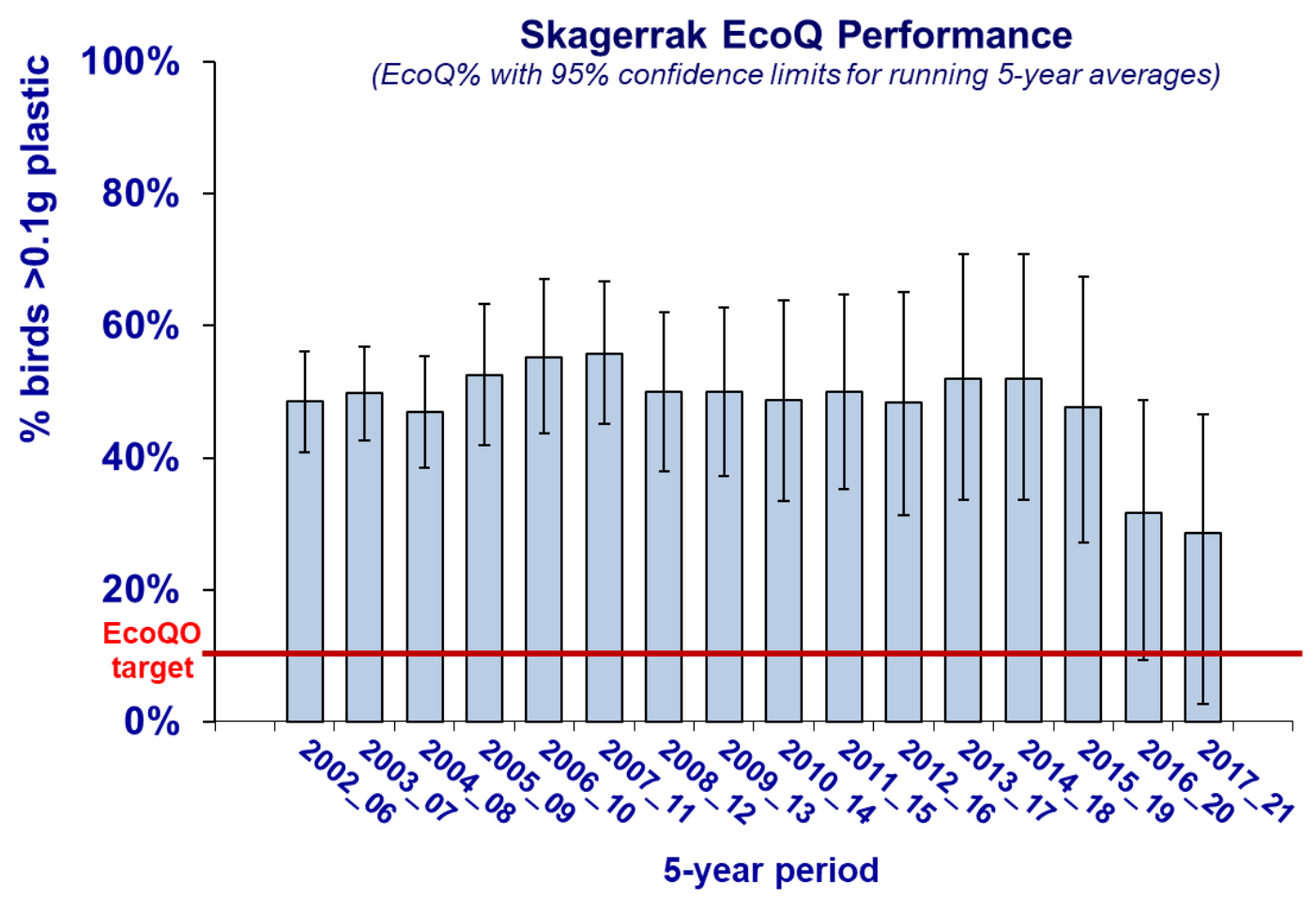

Figure 4 Running 5-year average values for EcoQ performance (EcoQ\%) since start of the monitoring in 2002. The red line shows the policy target that less than $10 \%$ of the stomachs should be over 0.1 gram of plastic.

Data underlying graphs in the above graphs can be found in the tables provided at the end of this report.

\section{Conclusion}

Fulmar stomach contents from around the Skagerrak suggest a downward pattern in the quantity of plastics since 2002. This is seen in both industrial plastic pellets as in user plastics, the remains of consumer plastics. Unfortunately these cannot be shown to be statistically significant. However, the patterns observed support the larger dataset for the whole of the North Sea, which has been shown to reflect a slow but statistically significant decrease from 2002-to 2018. Local studies such as around the Skagerrak are an essential component of the larger scale datasets. 
Photo info pages for fulmars in the recent 2017-2021 period.

\section{Overview of plastics in stomachs of 14 fulmars found in the Skagerrak area 2017-21}

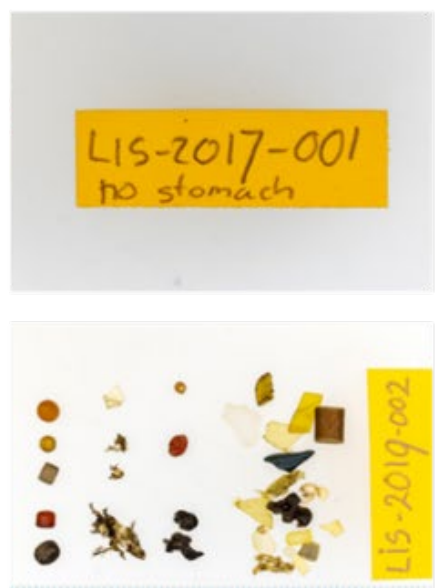

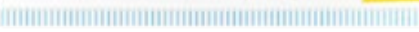
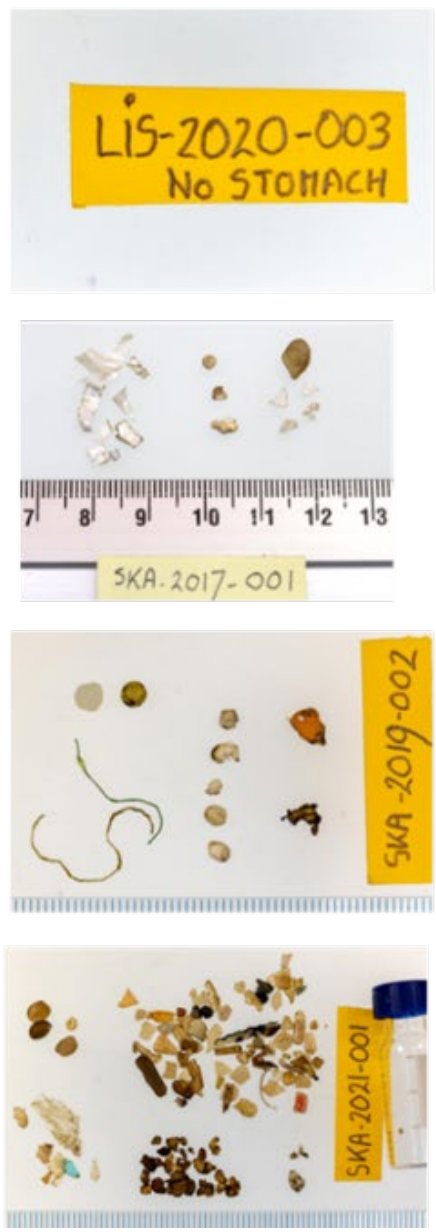
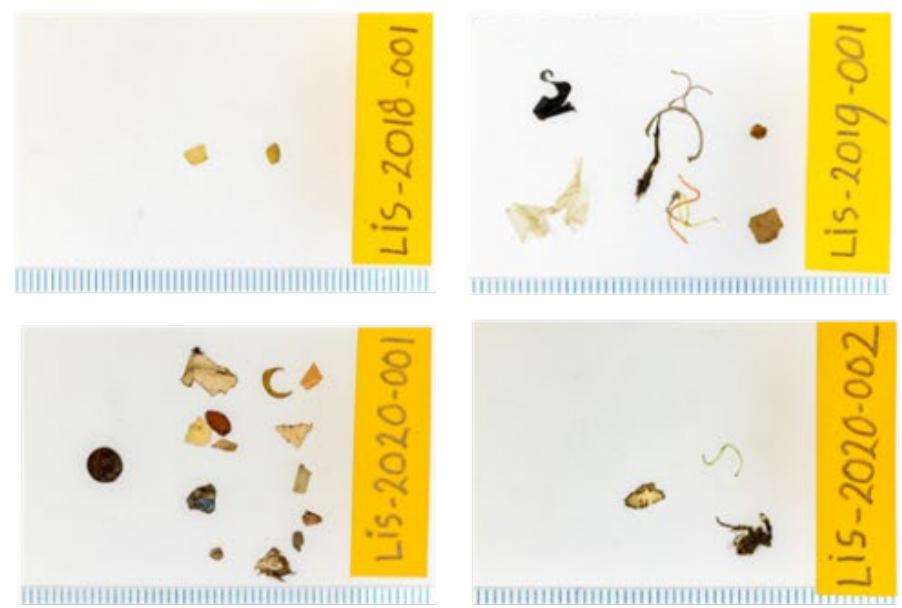

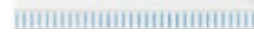
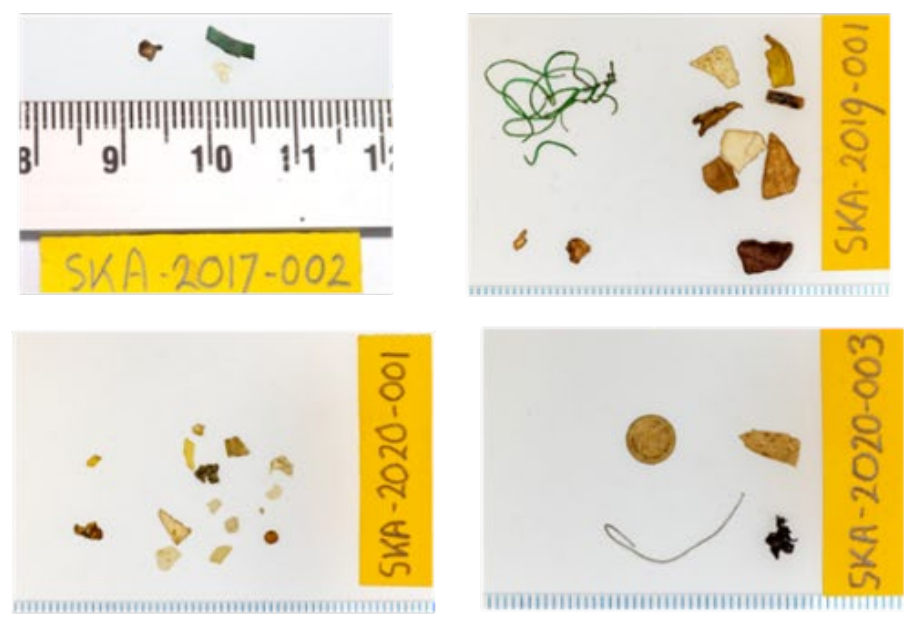

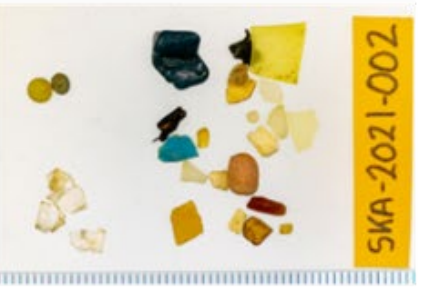




\section{Nr: $\quad$ SKA-2017-001}

\begin{tabular}{|l|l|}
\hline JAFCODE & SKA-2017-001 \\
\hline Country & Denmark \\
\hline Location & Skagen \\
\hline Date & 22-Jun-2017 \\
\hline Finder & John Pedersen \\
\hline Sex (Male, Female or UNKnown) & M \\
\hline Age (JUvenile, 2nd Year, IMmature, ADult, or UNK) & AD \\
\hline Colourphase (LL, L, D, DD or UNKnown) & LL \\
\hline $\begin{array}{l}\text { Condition score (0=fully emaciated to 9=excellent } \\
\text { condition) }\end{array}$ & 1 \\
\hline $\begin{array}{l}\text { Likely cause of death (STA=starvation for unknown } \\
\text { reason) }\end{array}$ & CAN \\
\hline Notes from dissection & $\begin{array}{l}\text { large cancer between oesophagus and } \\
\text { Proventriculus potentially obstructed food } \\
\text { passage; contents partly above }\end{array}$ \\
\hline nr of industrial plastic pellets & 0 \\
\hline nr of consumer debris plastic particles & 15 \\
\hline Total mass of plastic in stomach (g) & 0.0335 \\
\hline
\end{tabular}
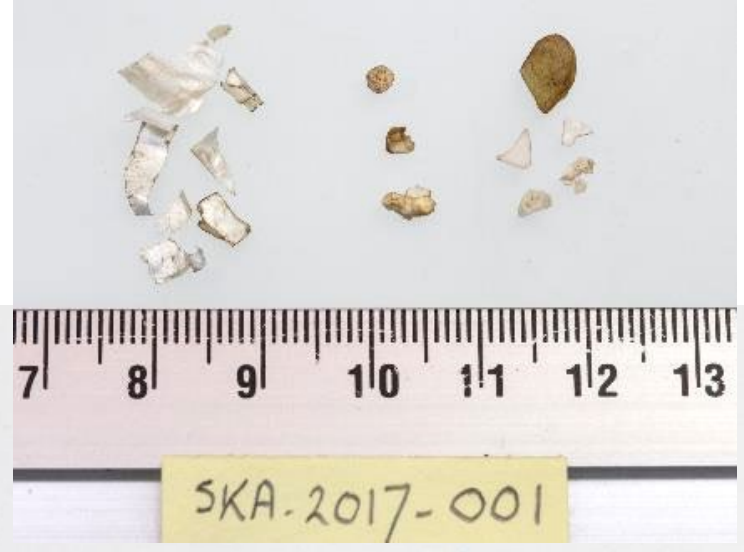


\section{Nr: $\quad$ SKA-2017-002}

\begin{tabular}{|l|l|}
\hline JAFCODE & SKA-2017-002 \\
\hline Country & Denmark \\
\hline Location & Skagen; Skiveren \\
\hline Date & 14-Aug-2017 \\
\hline Finder & Kaj Jacobsen via John Pedersen \\
\hline Sex (Male, Female or UNKnown) & M \\
\hline Age (JUvenile, 2nd Year, IMmature, ADult, or UNK) & IM \\
\hline Colourphase (LL, L, D, DD or UNKnown) & LL \\
\hline $\begin{array}{l}\text { Condition score (0=fully emaciated to 9=excellent } \\
\text { condition) }\end{array}$ & 1 \\
\hline $\begin{array}{l}\text { Likely cause of death (STA=starvation for } \\
\text { emaciated with unknown reason) }\end{array}$ & STA \\
\hline Notes from dissection & lung is bloody \\
\hline nr of industrial plastic pellets & 0 \\
\hline nr of consumer debris plastic particles & 3 \\
\hline Total mass of plastic in stomach (g) & 0.0033 \\
\hline
\end{tabular}

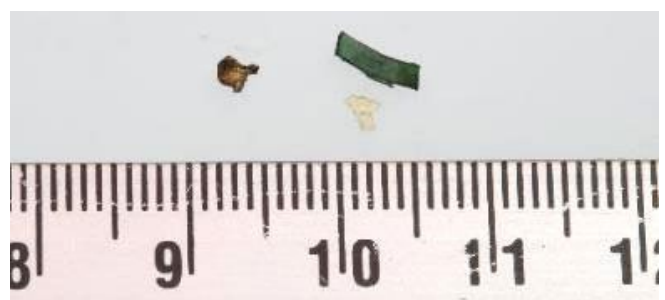

\section{SKA.2017-002}




\section{Nr: $\quad$ SKA-2019-001}

\begin{tabular}{|l|l|}
\hline JAFCODE & SKA-2019-001 \\
\hline Country & Denmark \\
\hline Location & Agger Tange; North Jutland \\
\hline Date & 14 -Sep-2019 \\
\hline Finder & Christian A. Jensen \\
\hline Sex (Male, Female or UNKnown) & M \\
\hline Age (JUvenile, $2^{\text {nd } Y e a r, ~ I M m a t u r e, ~ A D u l t, ~ o r ~ U N K) ~}$ & JU \\
\hline Colourphase (LL, L, D, DD or UNKnown) & LL \\
\hline $\begin{array}{l}\text { Condition score (0=fully emaciated to 9=excellent } \\
\text { condition) }\end{array}$ & 1 \\
\hline $\begin{array}{l}\text { Likely cause of death (STA=starvation for } \\
\text { emaciated with unknown reason) }\end{array}$ & COL \\
\hline Notes from dissection & sternum broken; worn tarsus joints but no rehab! \\
\hline nr of industrial plastic pellets & 0 \\
\hline nr of consumer debris plastic particles & 17 \\
\hline Total mass of plastic in stomach $(\mathrm{g})$ & 0.1142 \\
\hline
\end{tabular}
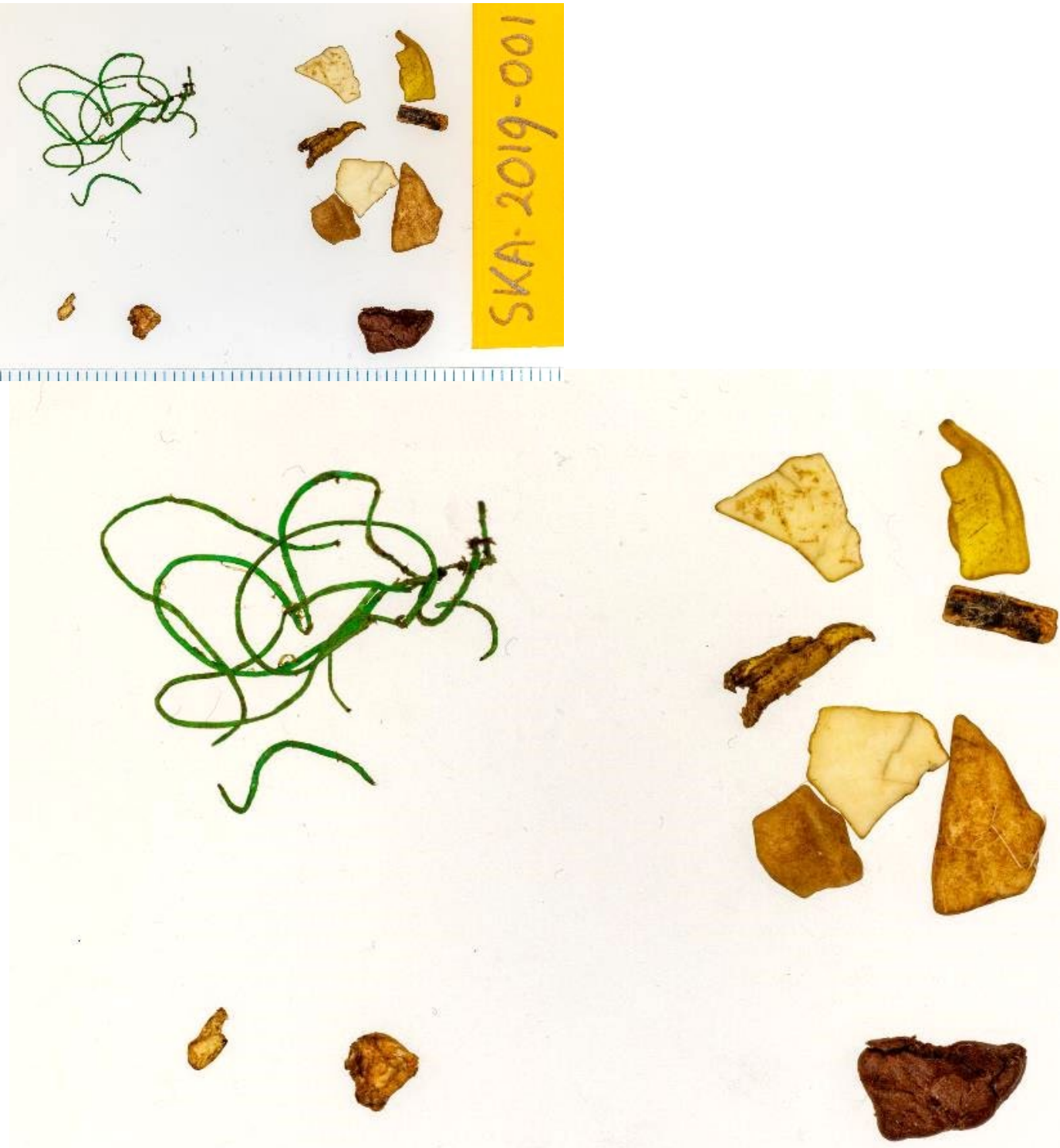


\section{Nr: $\quad$ SKA-2019-002}

\begin{tabular}{|l|l|}
\hline JAFCODE & SKA-2019-002 \\
\hline Country & Denmark \\
\hline Location & Skagen \\
\hline Date & 13-Aug-2019 \\
\hline Finder & John Pedersen \\
\hline Sex (Male, Female or UNKnown) & F \\
\hline Age (JUvenile, 2nd Year, IMmature, ADult, or UNK) & UNK \\
\hline Colourphase (LL, L, D, DD or UNKnown) & LL \\
\hline $\begin{array}{l}\text { Condition score (0=fully emaciated to 9=excellent } \\
\text { condition) }\end{array}$ & unknown \\
\hline $\begin{array}{l}\text { Likely cause of death (STA=starvation for } \\
\text { emaciated with unknown reason) }\end{array}$ & UNK \\
\hline Notes from dissection & X \\
\hline nr of industrial plastic pellets & 2 \\
\hline nr of consumer debris plastic particles & 9 \\
\hline Total mass of plastic in stomach (g) & 0.0598 \\
\hline
\end{tabular}

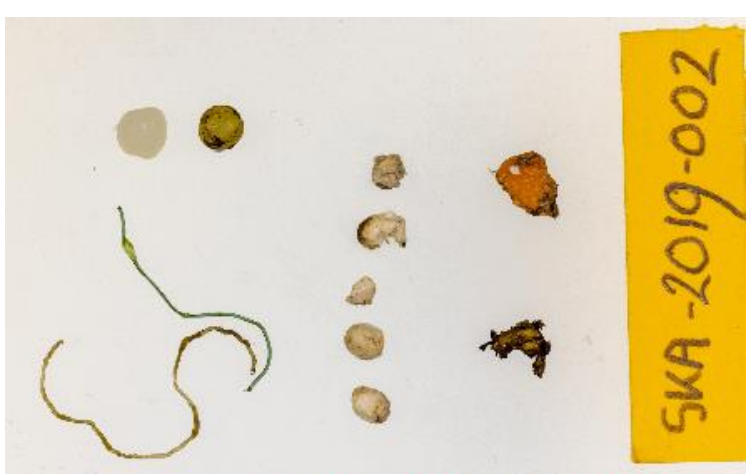

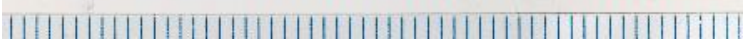

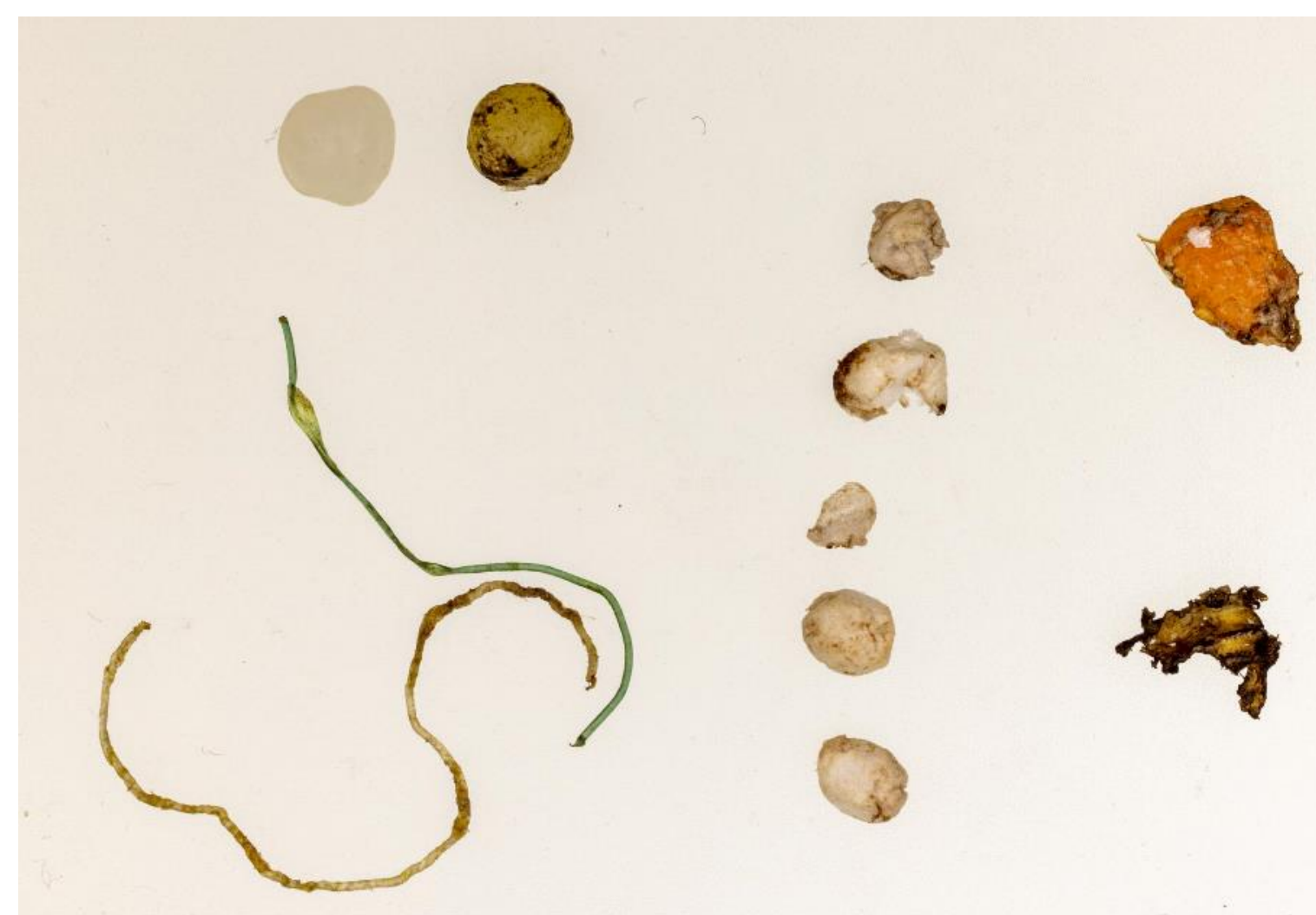




\section{Nr: $\quad$ SKA-2020-001}

\begin{tabular}{|l|l|}
\hline JAFCODE & SKA-2020-001 \\
\hline Country & Denmark \\
\hline Location & Skagen \\
\hline Date & $28-$ May-2020 \\
\hline Finder & Kaj Jacobsen \\
\hline Sex (Male, Female or UNKnown) & F \\
\hline Age (JUvenile, $2^{\text {nd }}$ Year, IMmature, ADult, or UNK) & AD \\
\hline Colourphase (LL, L, D, DD or UNKnown) & LL \\
\hline $\begin{array}{l}\text { Condition score (0=fully emaciated to 9=excellent } \\
\text { condition) }\end{array}$ & 1 \\
\hline $\begin{array}{l}\text { Likely cause of death (STA=starvation for } \\
\text { emaciated with unknown reason) }\end{array}$ & CEM \\
\hline Notes from dissection & $\begin{array}{l}\text { hard-shelled egg inside stopped by cement cloaca } \\
(41 \times 28 \mathrm{~mm})\end{array}$ \\
\hline nr of industrial plastic pellets & 0 \\
\hline nr of consumer debris plastic particles & 15 \\
\hline Total mass of plastic in stomach (g) & 0.041 \\
\hline & \\
\hline
\end{tabular}
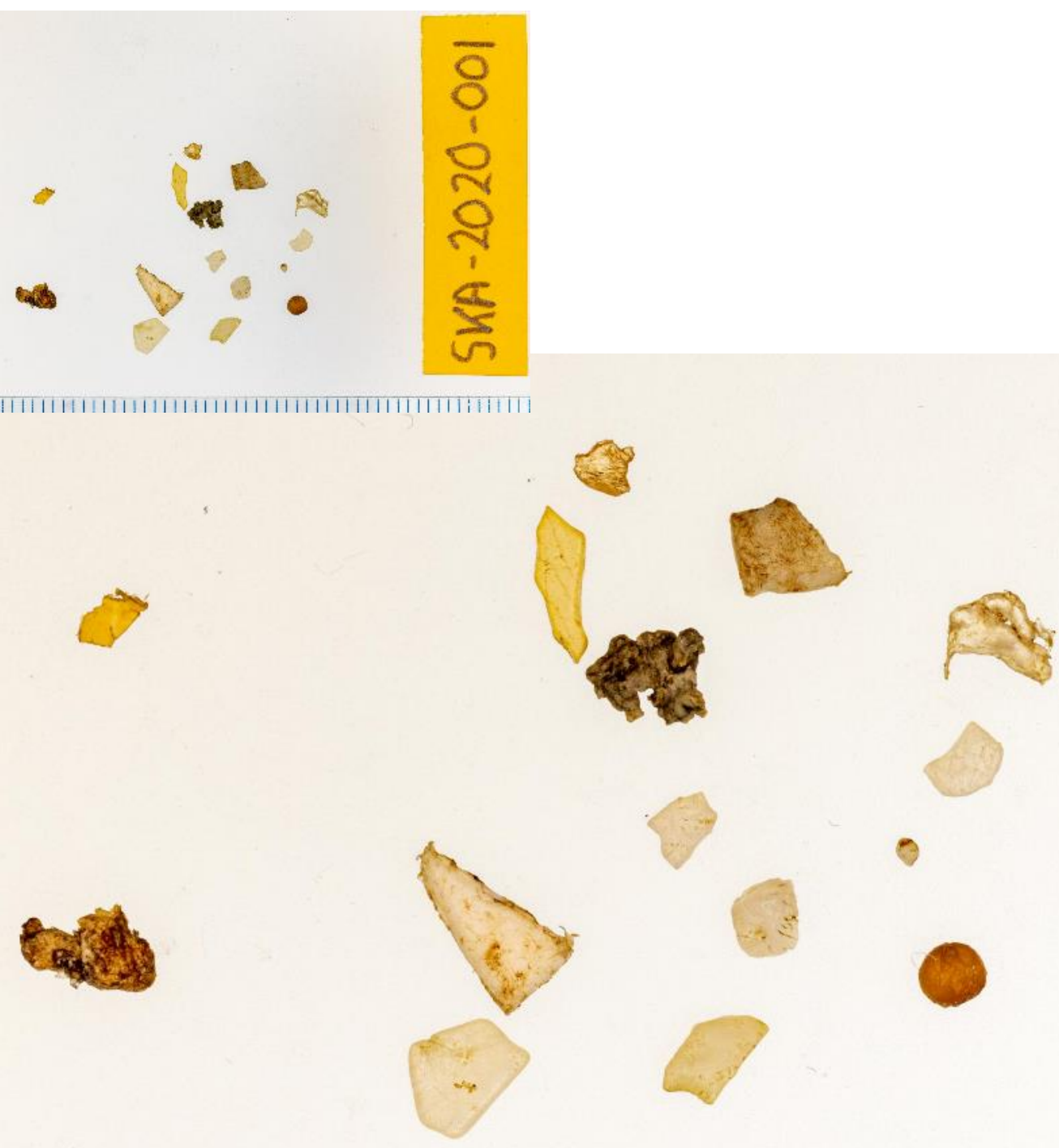


\section{Nr: $\quad$ SKA-2020-002}

\begin{tabular}{|l|l|}
\hline JAFCODE & SKA-2020-002 \\
\hline Country & Denmark \\
\hline Location & Kandesterne Skagen \\
\hline Date & $21-J u n-2020$ \\
\hline Finder & Kaj Jacobsen \\
\hline Sex (Male, Female or UNKnown) & F \\
\hline Age (JUvenile, 2 ${ }^{\text {nd } Y e a r, ~ I M m a t u r e, ~ A D u l t, ~ o r ~ U N K) ~}$ & IM \\
\hline Colourphase (LL, L, D, DD or UNKnown) & LL \\
\hline $\begin{array}{l}\text { Condition score (0=fully emaciated to 9=excellent } \\
\text { condition) }\end{array}$ & 2 \\
\hline $\begin{array}{l}\text { Likely cause of death (STA=starvation for } \\
\text { emaciated with unknown reason) }\end{array}$ & STA \\
\hline Notes from dissection & throat open presumed scavenging \\
\hline nr of industrial plastic pellets & 2 \\
\hline nr of consumer debris plastic particles & 19 \\
\hline Total mass of plastic in stomach (g) & 0.0843 \\
\hline
\end{tabular}
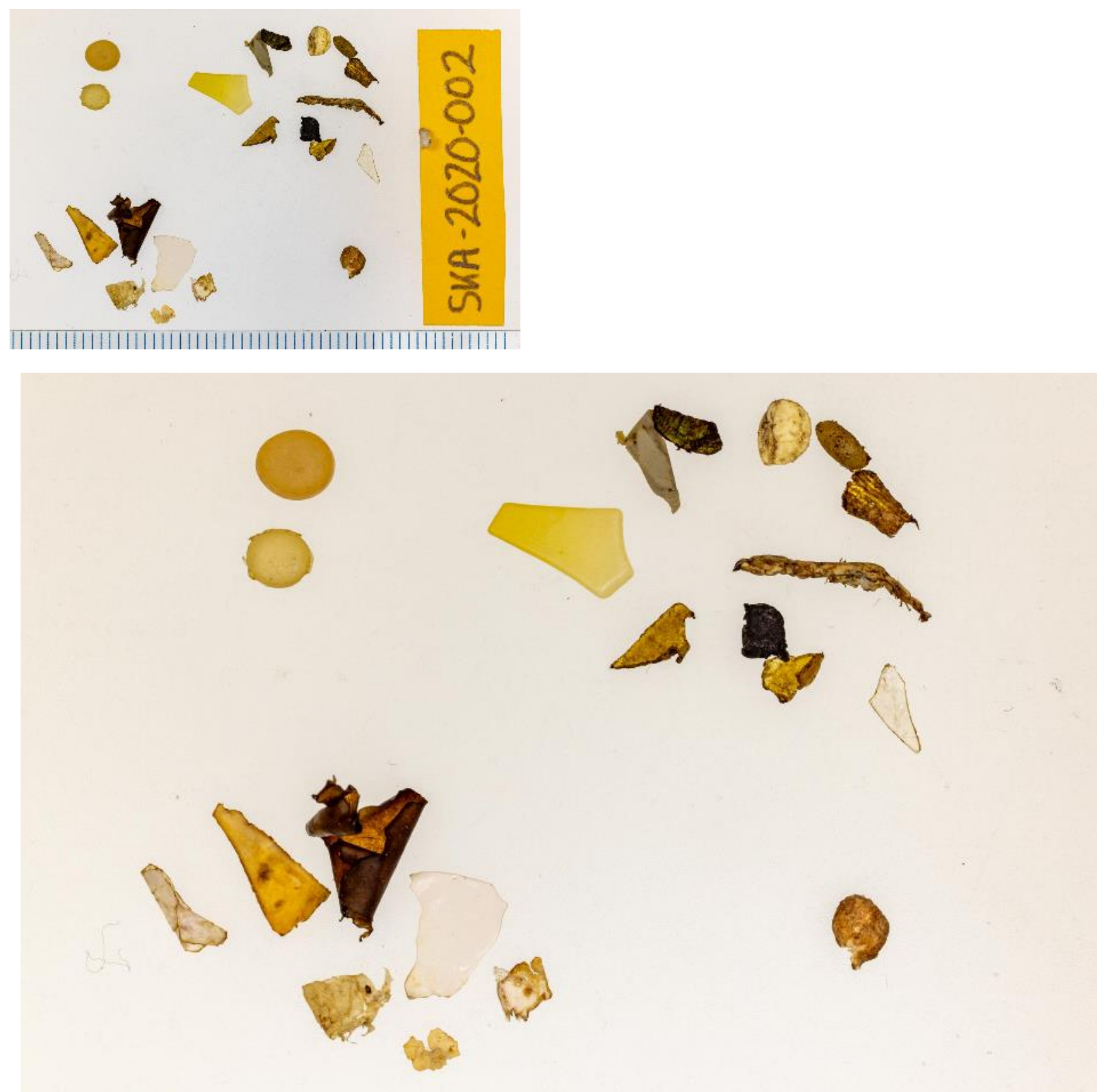


\section{Nr: $\quad$ SKA-2020-003}

\begin{tabular}{|l|l|}
\hline JAFCODE & SKA-2020-003 \\
\hline Country & Denmark \\
\hline Location & Skagen \\
\hline Date & 28-May-2020 \\
\hline Finder & Kaj Jacobsen \\
\hline Sex (Male, Female or UNKnown) & M \\
\hline Age (JUvenile, 2nd Year, IMmature, ADult, or UNK) & IM \\
\hline Colourphase (LL, L, D, DD or UNKnown) & LL \\
\hline $\begin{array}{l}\text { Condition score (0=fully emaciated to } 9=\text { excellent } \\
\text { condition) }\end{array}$ & 1 \\
\hline $\begin{array}{l}\text { Likely cause of death (STA=starvation for } \\
\text { emaciated with unknown reason) }\end{array}$ & STA \\
\hline Notes from dissection & bill tip broken; old torn foot web \\
\hline nr of industrial plastic pellets & 1 \\
\hline nr of consumer debris plastic particles & 3 \\
\hline Total mass of plastic in stomach (g) & 0.0192 \\
\hline
\end{tabular}
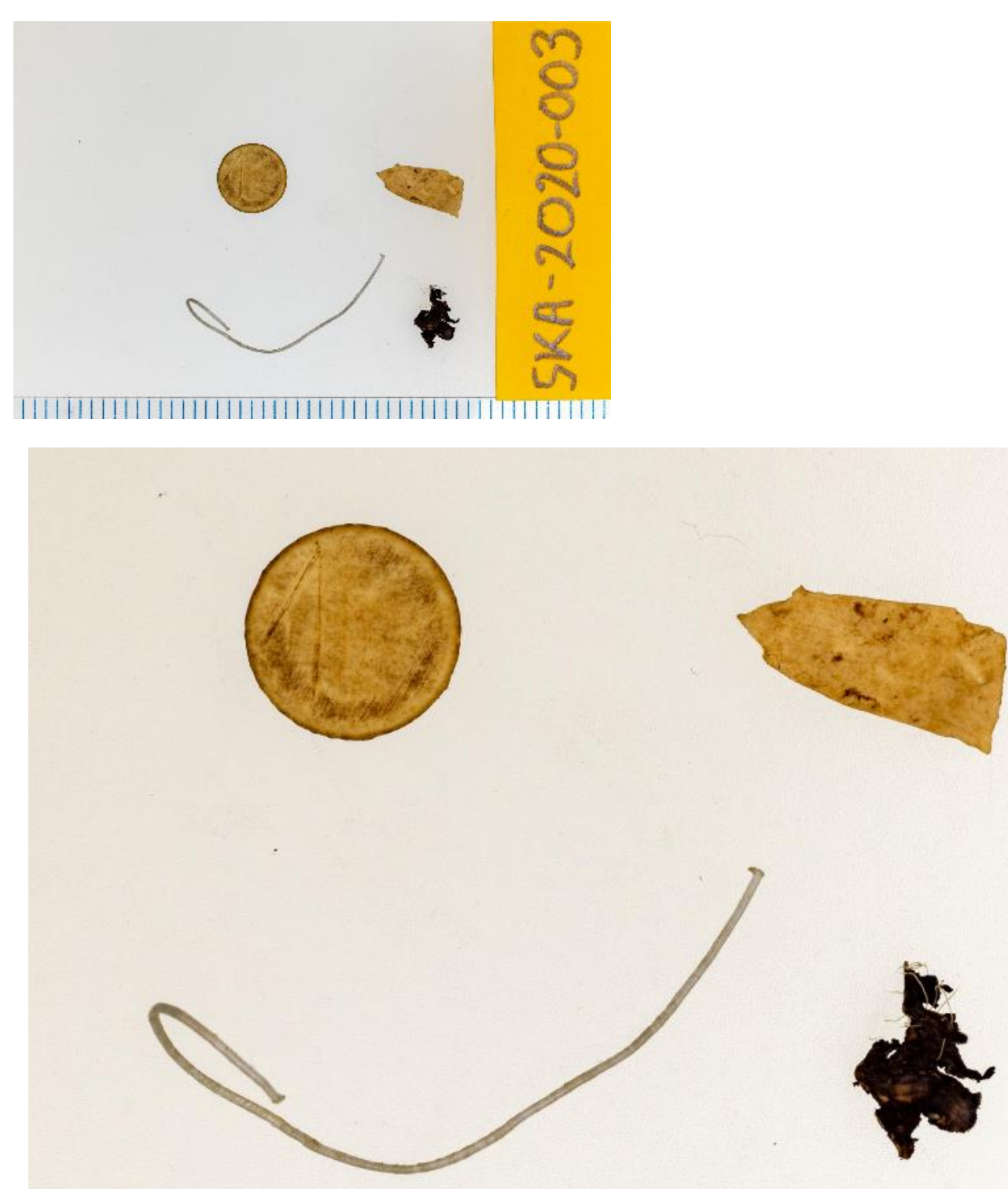


\section{Nr: $\quad$ SKA-2021-0021}

\begin{tabular}{|l|l|}
\hline JAFCODE & SKA-2021-001 \\
\hline Country & Denmark \\
\hline Location & Skagen \\
\hline Date & 24-Mar-2021 \\
\hline Finder & Skagen Bird Observatory \\
\hline Sex (Male, Female or UNKnown) & F \\
\hline Age (JUvenile, 2nd Year, IMmature, ADult, or UNK) & 2 Y \\
\hline Colourphase (LL, L, D, DD or UNKnown) & LL \\
\hline $\begin{array}{l}\text { Condition score (0=fully emaciated to 9=excellent } \\
\text { condition) }\end{array}$ & 1 \\
\hline $\begin{array}{l}\text { Likely cause of death (STA=starvation for } \\
\text { emaciated with unknown reason) }\end{array}$ & STA \\
\hline Notes from dissection & $\begin{array}{l}\text { legs missing postmortem; gut near cloaca filled with } \\
\text { grid (not cemented) }\end{array}$ \\
\hline nr of industrial plastic pellets & 4 \\
\hline nr of consumer debris plastic particles & 107 \\
\hline Total mass of plastic in stomach (g) & 0.3798 \\
\hline &
\end{tabular}

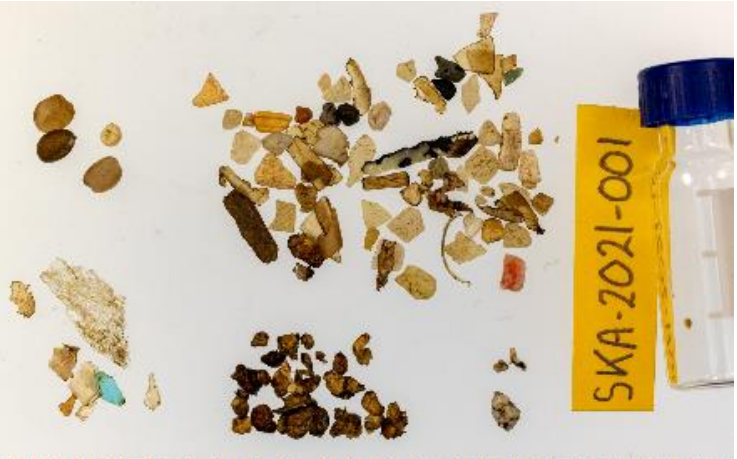

The small glass jar on the right contains a small bit of

decaying balloon rubber latex

\section{|| || || || || || || || || || || || ||| || || || || || || || || || || || || || || || || ||||}

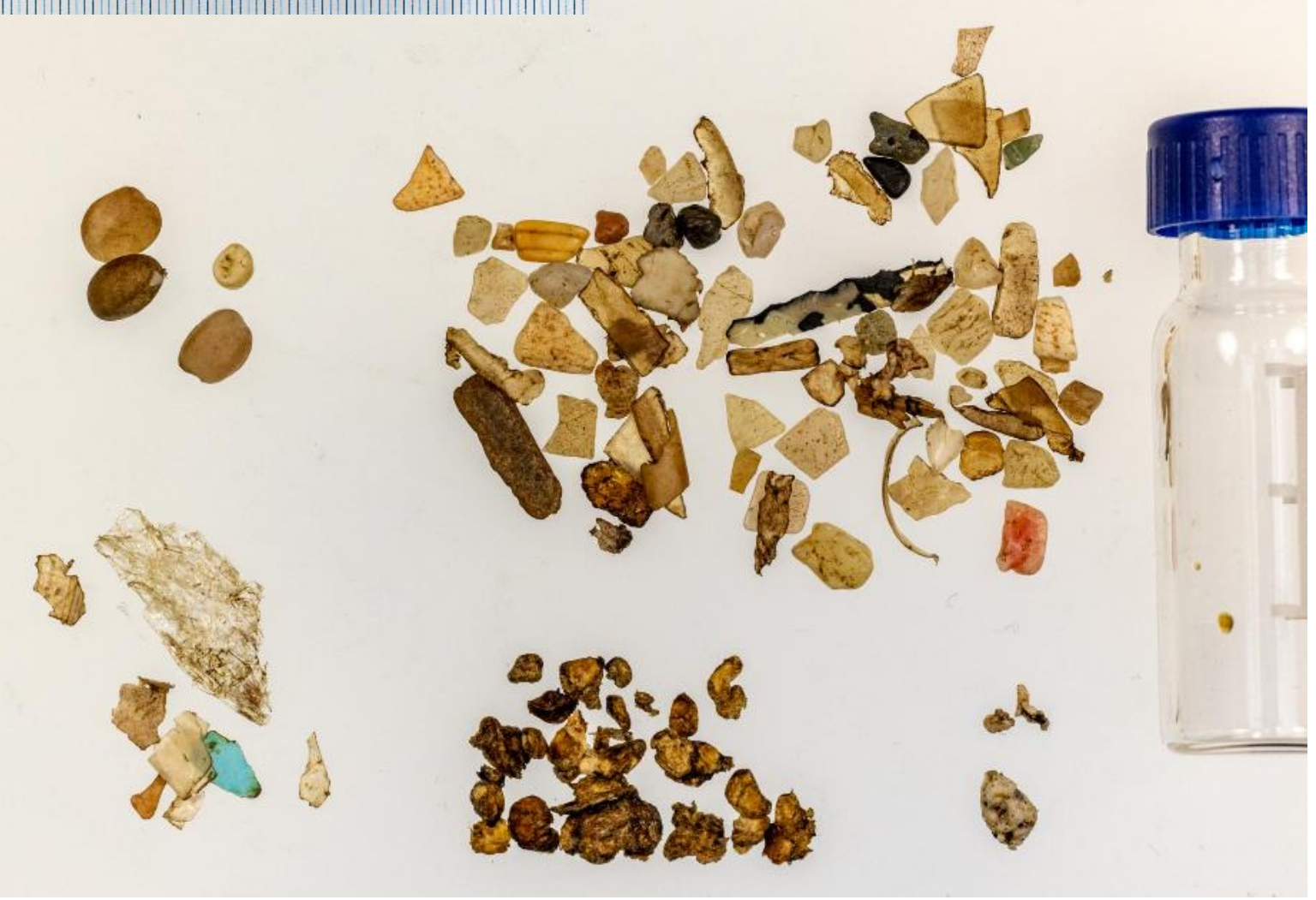




\section{Nr: $\quad$ SKA-2021-002}

\begin{tabular}{|l|l|}
\hline JAFCODE & SKA-2021-002 \\
\hline Country & Denmark \\
\hline Location & Skagen \\
\hline Date & 15 -Feb-2021 \\
\hline Finder & Skagen Bird Observatory \\
\hline Sex (Male, Female or UNKnown) & M \\
\hline Age (JUvenile, 2nd Year, IMmature, ADult, or UNK) & $2 \mathrm{Y}$ \\
\hline Colourphase (LL, L, D, DD or UNKnown) & LL \\
\hline $\begin{array}{l}\text { Condition score (0=fully emaciated to 9=excellent } \\
\text { condition) }\end{array}$ & 6 \\
\hline $\begin{array}{l}\text { Likely cause of death (STA=starvation for } \\
\text { emaciated with unknown reason) }\end{array}$ & OIL \\
\hline Notes from dissection & $\begin{array}{l}\text { exact date not known; right testis more normal } \\
\text { shape; cause of death oil but also arrested moult }\end{array}$ \\
\hline nr of industrial plastic pellets & 2 \\
\hline nr of consumer debris plastic particles & 25 \\
\hline Total mass of plastic in stomach (g) & 0.3585 \\
\hline & \\
\hline
\end{tabular}
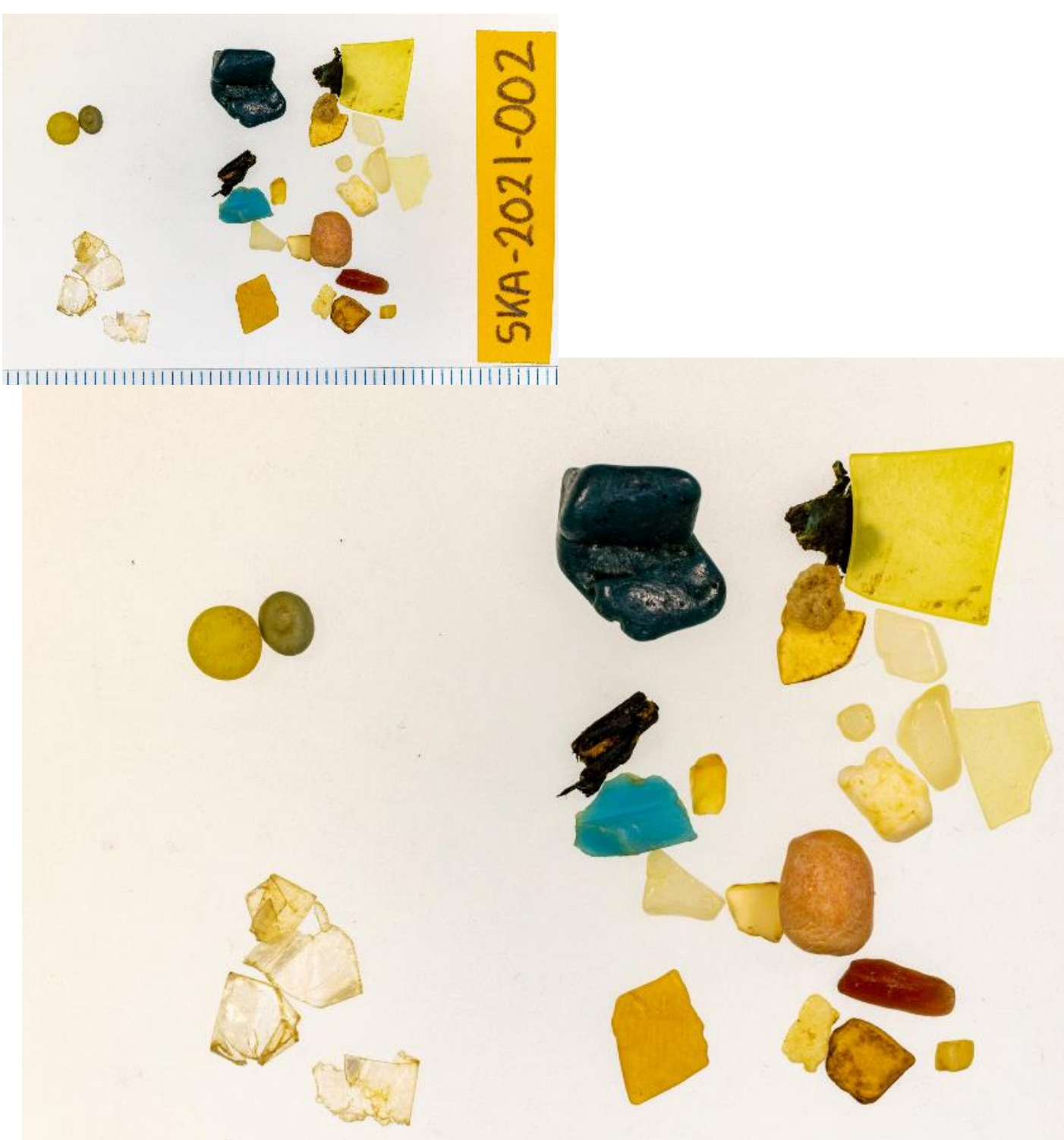


\section{Nr: $\quad$ LIS-2017-001}

\begin{tabular}{|l|l|}
\hline JAFCODE & LIS-2017-001 \\
\hline Country & Norway \\
\hline Location & Husebysanden; Lista \\
\hline Date & 3-Oct-2017 \\
\hline Finder & Kare Olsen \\
\hline Sex (Male, Female or UNKnown) & UNK \\
\hline Age (JUvenile, 2nd Year, IMmature, ADult, or UNK) & UNK \\
\hline Colourphase (LL, L, D, DD or UNKnown) & LL \\
\hline $\begin{array}{l}\text { Condition score (0=fully emaciated to 9=excellent } \\
\text { condition) }\end{array}$ & 2 \\
\hline $\begin{array}{l}\text { Likely cause of death (STA=starvation for } \\
\text { emaciated with unknown reason) }\end{array}$ & UNK \\
\hline Notes from dissection & heavily scavenged - NO STOMACH \\
\hline nr of industrial plastic pellets & heavily scavenged - NO STOMACH \\
\hline nr of consumer debris plastic particles & heavily scavenged - NO STOMACH \\
\hline Total mass of plastic in stomach (g) & heavily scavenged - NO STOMACH \\
\hline
\end{tabular}

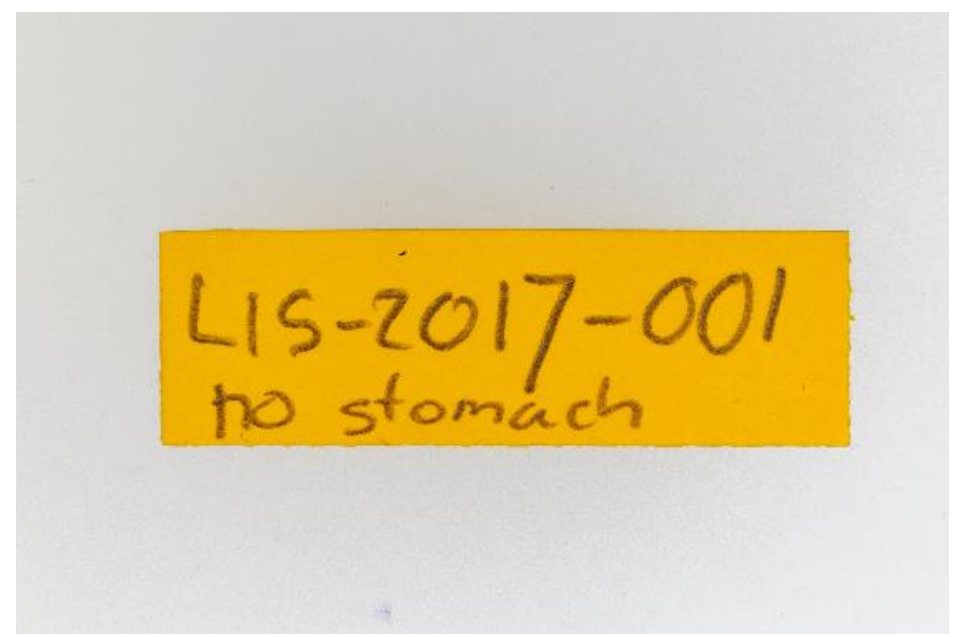




\section{Nr: LIS-2018-001}

\begin{tabular}{|c|c|}
\hline JAFCODE & LIS-2018-001 \\
\hline Country & Norway \\
\hline Location & Hanagersanden; Lista \\
\hline Date & $17-$ Oct-2018 \\
\hline Finder & Kare Olsen \\
\hline Sex (Male, Female or UNKnown) & $\mathrm{M}$ \\
\hline Age (JUvenile, $2^{\text {nd }}$ Year, IMmature, ADult, or UNK) & IM \\
\hline Colourphase (LL, L, D, DD or UNKnown) & LL \\
\hline $\begin{array}{l}\text { Condition score ( } 0=\text { fully emaciated to } 9=\text { excellent } \\
\text { condition) }\end{array}$ & 1 \\
\hline $\begin{array}{l}\text { Likely cause of death (STA=starvation for } \\
\text { emaciated with unknown reason) }\end{array}$ & STA \\
\hline Notes from dissection & one leg missing postmortem; swollen and wet gut \\
\hline $\mathrm{nr}$ of industrial plastic pellets & 0 \\
\hline $\mathrm{nr}$ of consumer debris plastic particles & 2 \\
\hline Total mass of plastic in stomach $(\mathrm{g})$ & 0.0068 \\
\hline
\end{tabular}

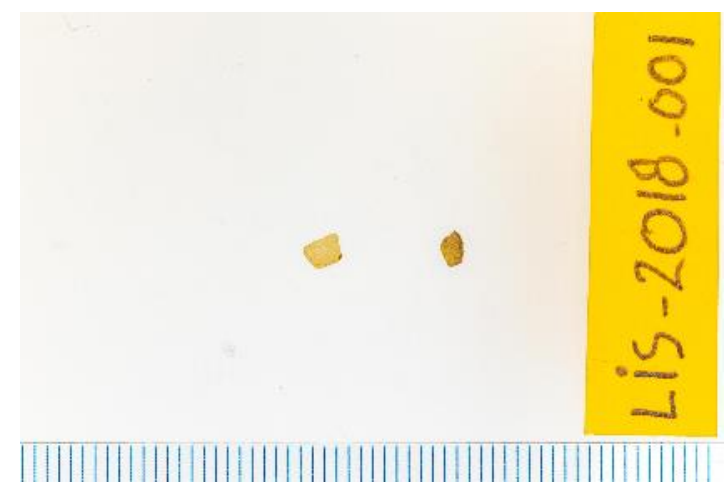




\section{Nr: LIS-2019-001}

\begin{tabular}{|l|l|}
\hline JAFCODE & LIS-2019-001 \\
\hline Country & Norway \\
\hline Location & Kadestranda; Lista \\
\hline Date & $7-$-Oct-2019 \\
\hline Finder & Kare Olsen \\
\hline Sex (Male, Female or UNKnown) & F \\
\hline Age (JUvenile, 2nd Year, IMmature, ADult, or UNK) & AD \\
\hline Colourphase (LL, L, D, DD or UNKnown) & LL \\
\hline $\begin{array}{l}\text { Condition score (0=fully emaciated to 9=excellent } \\
\text { condition) }\end{array}$ & 0 \\
\hline $\begin{array}{l}\text { Likely cause of death (STA=starvation for } \\
\text { emaciated with unknown reason) }\end{array}$ & STA \\
\hline Notes from dissection & $\begin{array}{l}\text { Kare suggested bycatch victim (broken wing; head } \\
\text { and leg missing) but body/organ condition do not } \\
\text { confirm bycatch }\end{array}$ \\
\hline nr of industrial plastic pellets & 0 \\
\hline nr of consumer debris plastic particles & 9 \\
\hline Total mass of plastic in stomach (g) & 0.0278 \\
\hline
\end{tabular}

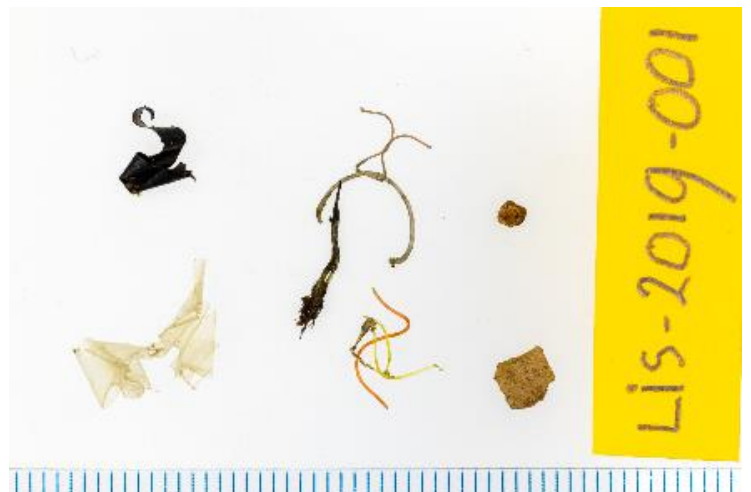

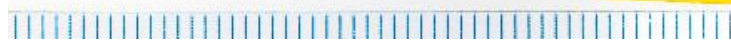
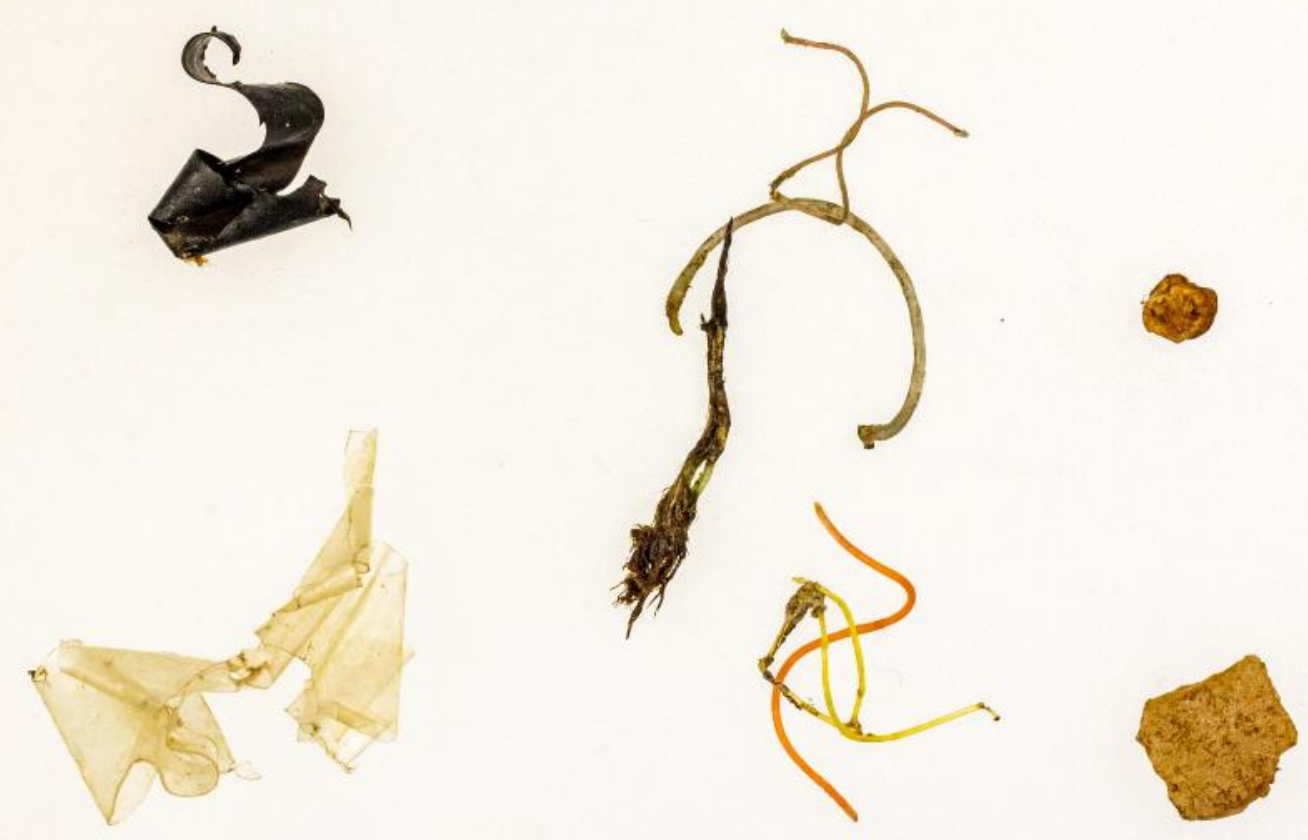


\section{Nr: $\quad$ LIS-2019-002}

\begin{tabular}{|l|l|}
\hline JAFCODE & LIS-2019-002 \\
\hline Country & Norway \\
\hline Location & Skiphaugsanden; Havika; Lista \\
\hline Date & 10 -Feb-2019 \\
\hline Finder & Tor O. Hansen \& Nils H. Lorentzen \\
\hline Sex (Male, Female or UNKnown) & F \\
\hline Age (UUvenile, 2nd Year, IMmature, ADult, or UNK) & 2 Y \\
\hline Colourphase (LL, L, D, DD or UNKnown) & LL \\
\hline $\begin{array}{l}\text { Condition score (0=fully emaciated to 9=excellent } \\
\text { condition) }\end{array}$ & 9 \\
\hline $\begin{array}{l}\text { Likely cause of death (STA=starvation for } \\
\text { emaciated with unknown reason) }\end{array}$ & DRO \\
\hline $\begin{array}{l}\text { Notes from dissection } \\
\text { nr of industrial plastic pellets }\end{array}$ & $\begin{array}{l}\text { Kare suggested bycatch victim (broken wing; head } \\
\text { and leg missing) internal condition confirms } \\
\text { drowning }\end{array}$ \\
\hline nr of consumer debris plastic particles & 5 \\
\hline Total mass of plastic in stomach (g) & 29 \\
\hline
\end{tabular}

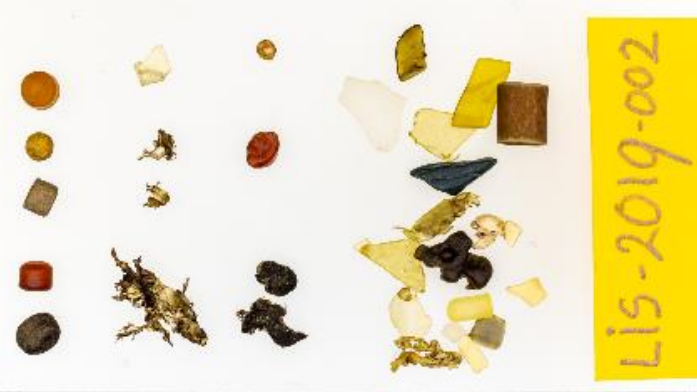

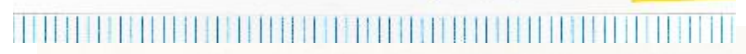
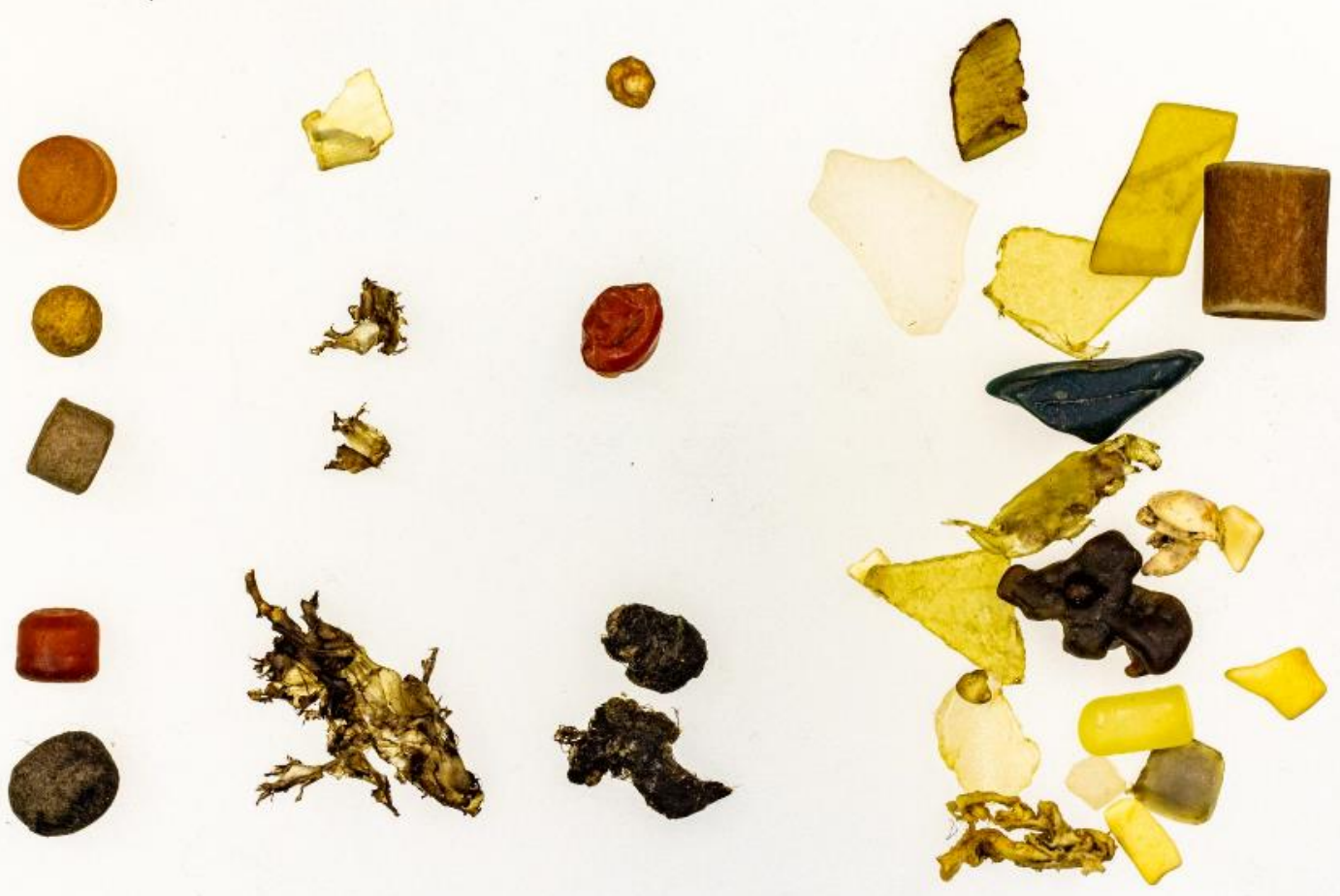


\section{Nr: $\quad$ LIS-2020-001}

\begin{tabular}{|l|l|}
\hline JAFCODE & LIS-2020-001 \\
\hline Country & Norway \\
\hline Location & Tranevag; Lista \\
\hline Date & $25-$ Mar-2020 \\
\hline Finder & Kare Olsen \\
\hline Sex (Male, Female or UNKnown) & M \\
\hline Age (JUvenile, 2 ${ }^{\text {nd } Y e a r, ~ I M m a t u r e, ~ A D u l t, ~ o r ~ U N K) ~}$ & 2 Y \\
\hline Colourphase (LL, L, D, DD or UNKnown) & LL \\
\hline $\begin{array}{l}\text { Condition score (0=fully emaciated to 9=excellent } \\
\text { condition) }\end{array}$ & 1 \\
\hline $\begin{array}{l}\text { Likely cause of death (STA=starvation for } \\
\text { emaciated with unknown reason) }\end{array}$ & GUT \\
\hline Notes from dissection & kidneys very granular \\
\hline nr of industrial plastic pellets & 1 \\
\hline nr of consumer debris plastic particles & 13 \\
\hline Total mass of plastic in stomach (g) & 0.0737 \\
\hline
\end{tabular}

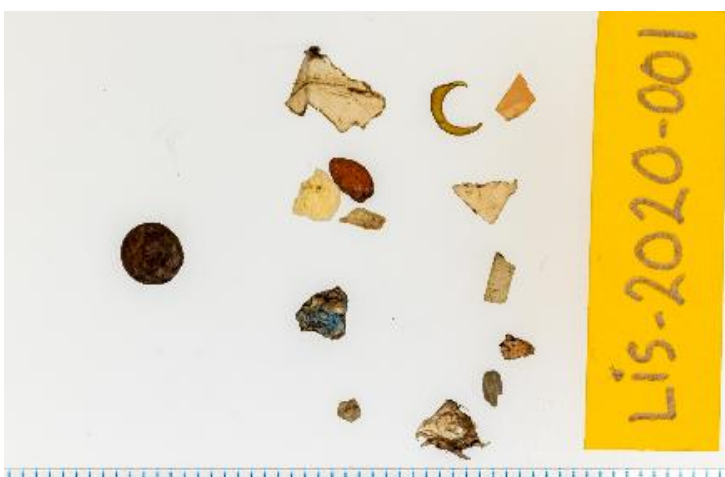

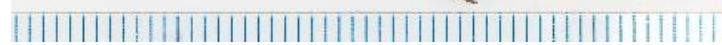
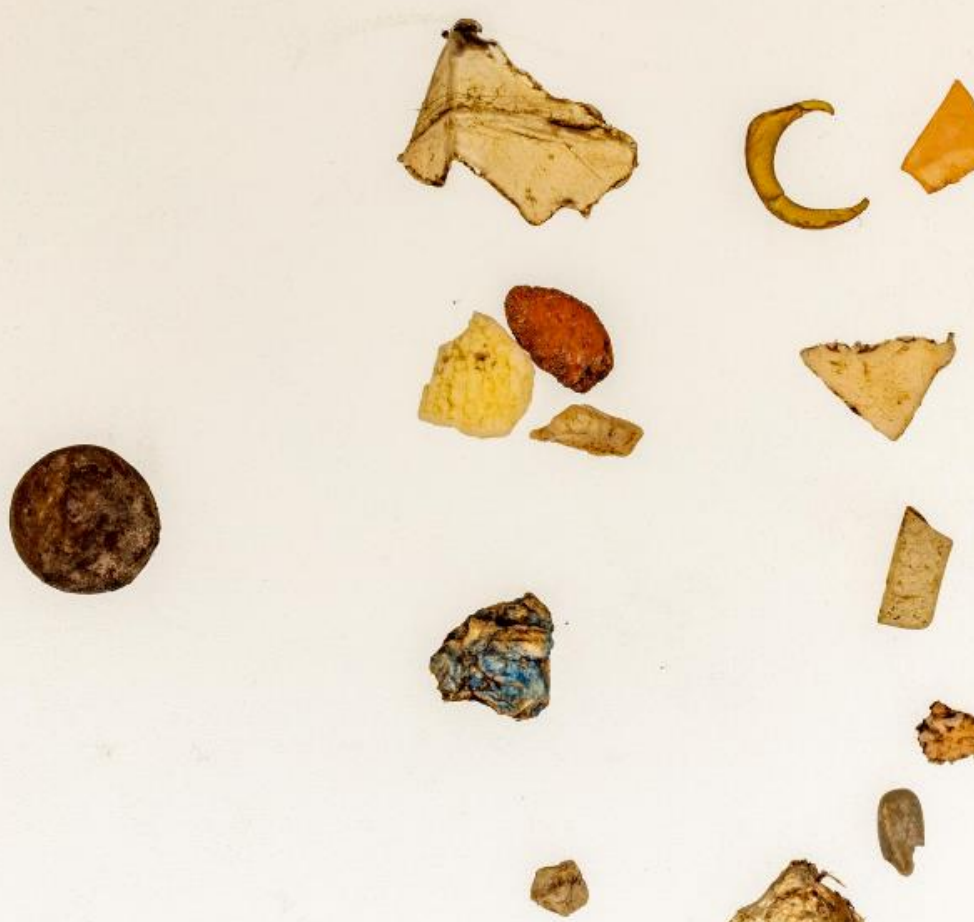


\section{Nr: $\quad$ LIS-2020-002}

\begin{tabular}{|l|l|}
\hline JAFCODE & LIS-2020-002 \\
\hline Country & Norway \\
\hline Location & Nordhasselstranden; Lista \\
\hline Date & $18-$ Feb-2020 \\
\hline Finder & Kare Olsen \\
\hline Sex (Male, Female or UNKnown) & M \\
\hline Age (JUvenile, 2nd Year, IMmature, ADult, or UNK) & IM \\
\hline Colourphase (LL, L, D, DD or UNKnown) & LL \\
\hline $\begin{array}{l}\text { Condition score (0=fully emaciated to 9=excellent } \\
\text { condition) }\end{array}$ & 5 \\
\hline $\begin{array}{l}\text { Likely cause of death (STA=starvation for } \\
\text { emaciated with unknown reason) }\end{array}$ & DRO \\
\hline Notes from dissection & good health condition indicates unnatural death \\
\hline nr of industrial plastic pellets & 0 \\
\hline nr of consumer debris plastic particles & 3 \\
\hline Total mass of plastic in stomach (g) & 0.004 \\
\hline
\end{tabular}
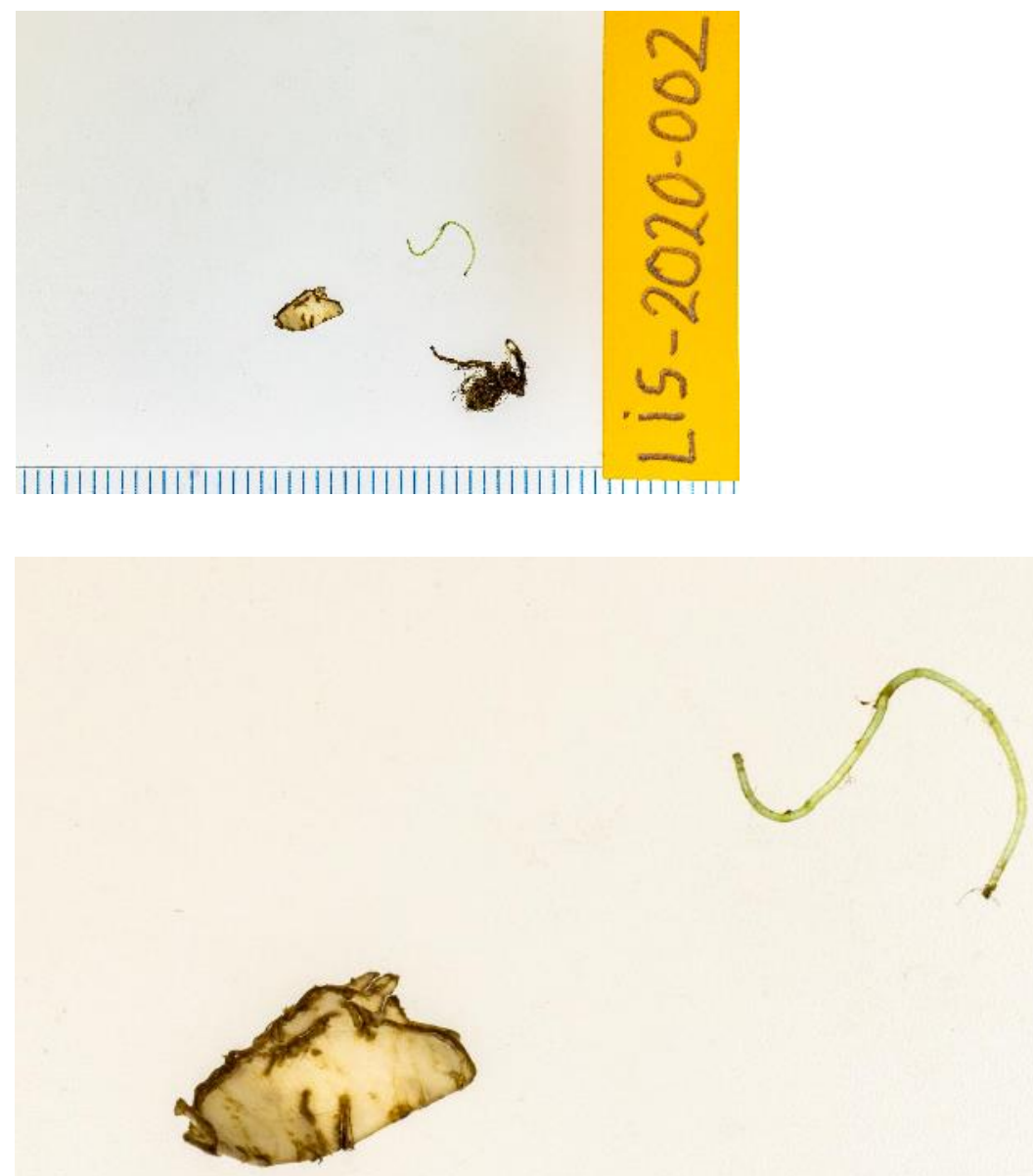


\section{Nr: $\quad$ LIS-2020-003}

\begin{tabular}{|l|l|}
\hline JAFCODE & LIS-2020-003 \\
\hline Country & Norway \\
\hline Location & Kviljostranden; Lista \\
\hline Date & 22-Aug-2020 \\
\hline Finder & Knut S. Olsen \\
\hline Sex (Male, Female or UNKnown) & UNK \\
\hline Age (JUvenile, $2^{\text {nd } Y e a r, ~ I M m a t u r e, ~ A D u l t, ~ o r ~ U N K) ~}$ & UNK \\
\hline Colourphase (LL, L, D, DD or UNKnown) & LL \\
\hline $\begin{array}{l}\text { Condition score (0=fully emaciated to 9=excellent } \\
\text { condition) }\end{array}$ & unknown \\
\hline $\begin{array}{l}\text { Likely cause of death (STA=starvation for } \\
\text { emaciated with unknown reason) }\end{array}$ & UNK \\
\hline Notes from dissection & $\begin{array}{l}\text { mummified; gizzard missing; some plastic in } \\
\text { proventriculus remaining but not collected }\end{array}$ \\
\hline nr of industrial plastic pellets & No complete stomach \\
\hline nr of consumer debris plastic particles & No complete stomach \\
\hline Total mass of plastic in stomach (g) & No complete stomach \\
\hline
\end{tabular}

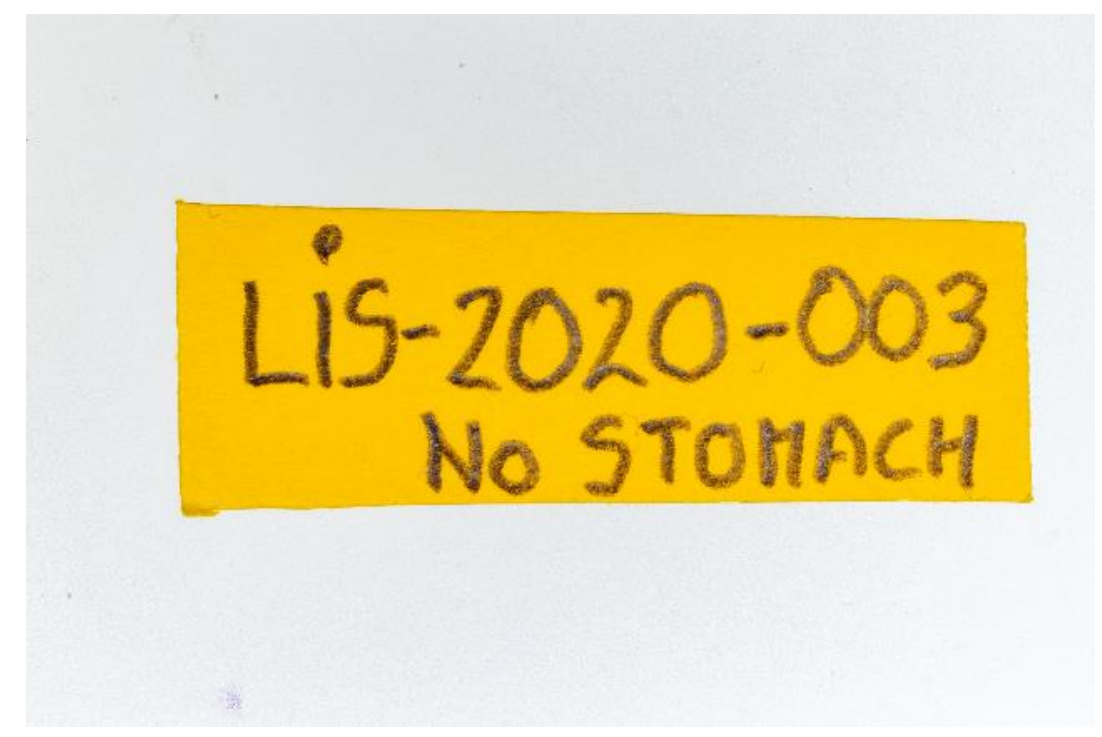




\section{Acknowledgements}

We are very grateful to John Pedersen, Poul Lindhard Hansen and Kåre Olav Olsen for organising the local beach surveys for fulmars. Through them we thank all helpers, there are simply too many to name individually. Our gratitude not only goes to those who found a bird shown in the photo pages of this report, but to all the volunteers who year after year have been on the lookout for fulmars suitable for the monitoring project. Their individual support represents an important contribution to high level marine litter policy decisions! The European Interreg IIIB program supported monitoring in Lista and Skagen from 2002 to 2004. A corporate social responsibility award from the NYK Group Europe Ltd (Nippon Yusen Kaisa shipping) to Jan van Franeker partly assisted the international continuation. The Dutch Ministry of Infrastructure supports the monitoring in the Netherlands since the year 2000 and supports incidental international reporting as in the reference cited below. The Danish Environmental Protection Agency supported the Skagen monitoring from 2014 to 2018.

\section{Reference}

For readability of this report we only refer to the large publication that dealt with North Sea wide data over the period 2002-2018. All relevant background documents are listed in the literature list of that paper.

Van Franeker, J.A., Kühn, S., Anker-Nilssen, T.,, Edwards, E.W.J., Gallien, F., Guse, N., Kakkonen, J.E., Mallory, M.L., Miles, W., Olsen, K.O., Pedersen, J., Provencher, J., Roos, M., Stienen, E., Turner, D.M. \& Van Loon, W.M.G.M. 2021. New tools to evaluate plastic ingestion by northern fulmars applied to North Sea monitoring data 2002-2018. Marine Pollution Bulletin 166: 112246 https://doi.org/10.1016/j.marpolbul.2021.112246 
Supplement 1: data details underlying graphs

Skagerrak (Lista, Norway and Skagen, Denmark)

Total plastics

\begin{tabular}{|c|c|c|c|c|c|c|}
\hline PERIOD & $\begin{array}{c}\text { sample } \\
n\end{array}$ & $\begin{array}{c}\text { Incide } \\
\text { nce } \\
\%\end{array}$ & $\begin{array}{c}\text { average } \\
\text { number } \\
\mathrm{n} \pm \mathrm{se}\end{array}$ & $\begin{array}{l}\text { average mass } \\
\quad \mathrm{g} \pm \mathrm{se}\end{array}$ & $\begin{array}{l}\text { Geometric } \\
\text { mean mass }\end{array}$ & $\begin{array}{c}\text { EcoQO \% } \\
\text { (over } 0.1 \mathrm{~g} \text { ) }\end{array}$ \\
\hline 2002_06 & 163 & $95 \%$ & $40.0 \pm 7.3$ & $0.35 \pm 0.13$ & 0.073 & $48 \%$ \\
\hline 2003_07 & 185 & $96 \%$ & $47.7 \pm 8.8$ & $0.35 \pm 0.11$ & 0.081 & $50 \%$ \\
\hline 2004_08 & 132 & $95 \%$ & $58.4 \pm 12.3$ & $0.42 \pm 0.16$ & 0.079 & $47 \%$ \\
\hline 2005_09 & 80 & $98 \%$ & $53.5 \pm 15.4$ & $0.31 \pm 0.05$ & 0.099 & $53 \%$ \\
\hline 2006_10 & 67 & $99 \%$ & $58.7 \pm 18.2$ & $0.32 \pm 0.06$ & 0.116 & $55 \%$ \\
\hline 2007_11 & 79 & $94 \%$ & $52.6 \pm 15.5$ & $0.31 \pm 0.05$ & 0.105 & $56 \%$ \\
\hline 2008_12 & 64 & $91 \%$ & $31.3 \pm 7.4$ & $0.26 \pm 0.05$ & 0.077 & $50 \%$ \\
\hline 2009_13 & 56 & $89 \%$ & $29.1 \pm 7.4$ & $0.25 \pm 0.05$ & 0.072 & $50 \%$ \\
\hline 2010_14 & 39 & $87 \%$ & $16.7 \pm 3.2$ & $0.18 \pm 0.03$ & 0.055 & $49 \%$ \\
\hline 2011_15 & 42 & $86 \%$ & $16.5 \pm 3.1$ & $0.17 \pm 0.03$ & 0.048 & $50 \%$ \\
\hline 2012_16 & 31 & $94 \%$ & $22.5 \pm 5.1$ & $0.14 \pm 0.03$ & 0.060 & $48 \%$ \\
\hline 2013_17 & 25 & $96 \%$ & $22.4 \pm 6.1$ & $0.14 \pm 0.03$ & 0.060 & $52 \%$ \\
\hline 2014_18 & 25 & $96 \%$ & $22.4 \pm 6.1$ & $0.14 \pm 0.03$ & 0.058 & $52 \%$ \\
\hline 2015_19 & 21 & $95 \%$ & $23.4 \pm 6.9$ & $0.15 \pm 0.04$ & 0.059 & $48 \%$ \\
\hline 2016_20 & 19 & $100 \%$ & $23.8 \pm 7.3$ & $0.13 \pm 0.04$ & 0.055 & $32 \%$ \\
\hline 2017_21 & 14 & $100 \%$ & $20.4 \pm 7.4$ & $0.11 \pm 0.04$ & 0.046 & $29 \%$ \\
\hline
\end{tabular}

Skagerrak (Lista, Norway and Skagen, Denmark)

\begin{tabular}{|c|c|c|c|c|c|c|c|}
\hline \multirow[b]{2}{*}{ PERIOD } & \multirow[b]{2}{*}{$\begin{array}{c}\text { sample } \\
n\end{array}$} & \multicolumn{3}{|c|}{ Industrial granules } & \multicolumn{3}{|c|}{ User plastics } \\
\hline & & $\begin{array}{l}\text { Inc. } \\
\%\end{array}$ & $\begin{array}{l}\text { avg number } \\
n \pm s e\end{array}$ & $\begin{array}{l}\text { avg mass } \\
\mathrm{g} \pm \mathrm{se}\end{array}$ & $\begin{array}{l}\text { Inc. } \\
\%\end{array}$ & $\begin{array}{l}\text { avg number } \\
n \pm \text { se }\end{array}$ & $\begin{array}{l}\text { avg mass } \\
\mathrm{g} \pm \mathrm{se}\end{array}$ \\
\hline 2002_06 & 163 & $59 \%$ & $3.0 \pm 0.5$ & $0.06 \pm 0.01$ & $95 \%$ & $37.0 \pm 7.0$ & $0.29 \pm 0.13$ \\
\hline 2003_07 & 185 & $61 \%$ & $3.2 \pm 0.5$ & $0.06 \pm 0.01$ & $96 \%$ & $44.4 \pm 8.6$ & $0.29 \pm 0.11$ \\
\hline 2004_08 & 132 & $58 \%$ & $3.5 \pm 0.7$ & $0.06 \pm 0.01$ & $95 \%$ & $54.9 \pm 11.9$ & $0.36 \pm 0.16$ \\
\hline 2005_09 & 80 & $54 \%$ & $3.1 \pm 0.7$ & $0.06 \pm 0.01$ & $98 \%$ & $50.3 \pm 14.8$ & $0.25 \pm 0.04$ \\
\hline 2006_10 & 67 & $55 \%$ & $3.5 \pm 0.9$ & $0.07 \pm 0.02$ & $99 \%$ & $55.2 \pm 17.5$ & $0.25 \pm 0.04$ \\
\hline 2007_11 & 79 & $53 \%$ & $3.4 \pm 0.8$ & $0.07 \pm 0.02$ & $94 \%$ & $49.2 \pm 14.9$ & $0.24 \pm 0.04$ \\
\hline 2008_12 & 64 & $41 \%$ & $2.5 \pm 0.8$ & $0.05 \pm 0.02$ & $91 \%$ & $28.8 \pm 6.8$ & $0.21 \pm 0.04$ \\
\hline 2009_13 & 56 & $36 \%$ & $2.2 \pm 0.7$ & $0.05 \pm 0.02$ & $89 \%$ & $27.0 \pm 6.9$ & $0.20 \pm 0.04$ \\
\hline 2010_14 & 39 & $33 \%$ & $1.4 \pm 0.6$ & $0.03 \pm 0.02$ & $87 \%$ & $15.3 \pm 2.9$ & $0.14 \pm 0.03$ \\
\hline 2011_15 & 42 & $38 \%$ & $1.5 \pm 0.6$ & $0.03 \pm 0.01$ & $86 \%$ & $15.0 \pm 2.8$ & $0.13 \pm 0.03$ \\
\hline 2012_16 & 31 & $42 \%$ & $1.6 \pm 0.5$ & $0.03 \pm 0.01$ & $94 \%$ & $20.9 \pm 4.7$ & $0.10 \pm 0.02$ \\
\hline 2013_17 & 25 & $48 \%$ & $1.8 \pm 0.6$ & $0.04 \pm 0.01$ & $96 \%$ & $20.6 \pm 5.5$ & $0.10 \pm 0.02$ \\
\hline 2014_18 & 25 & $48 \%$ & $1.8 \pm 0.6$ & $0.04 \pm 0.01$ & $96 \%$ & $20.5 \pm 5.6$ & $0.10 \pm 0.02$ \\
\hline 2015_19 & 21 & $48 \%$ & $2.1 \pm 0.7$ & $0.04 \pm 0.02$ & $95 \%$ & $21.3 \pm 6.2$ & $0.10 \pm 0.02$ \\
\hline 2016_20 & 19 & $53 \%$ & $2.1 \pm 0.8$ & $0.04 \pm 0.02$ & $100 \%$ & $21.7 \pm 6.7$ & $0.09 \pm 0.02$ \\
\hline 2017_21 & 14 & $50 \%$ & $1.2 \pm 0.4$ & $0.02 \pm 0.01$ & $100 \%$ & $19.2 \pm 7.1$ & $0.09 \pm 0.03$ \\
\hline
\end{tabular}


Supplement 2: causes of death (acronyms)

\section{CEM = cementcloaca}

A blockage in the final part of the intestine by a 'hard' egg-shaped ball formed by accumulation of layer upon layer of hardened faeces and ureum. At some stage this completely blocks defaecation, the parts of the intestine above this fill up with digested mud that can't be excreted.

\section{COL = collision}

Collision is used when we observe signs of a mechanical death, e.g. broken bones, or internal heavy bruises. These may be caused by collisions with cables, wires, ship- or lighthouse lights, cliff accidents, and also roadkills. Collision may lead to instant death, but also to a slow starvation in birds being injured and alive, but unable to provide themselves with food.

\section{DRO = drowning}

This is used when the birds appear healthy, and in good body condition, except for bloodfilled or soaked lungs. These things suggest that the bird may have drowned instantly in surface nets. This could also be on longline hooks but without visible damage from the longline (see below).

\section{LLV = long-line victim}

A specific case of drowning or entanglement. Evidence showing that the bird drowned from longline hooking or entanglement, where birds are drawn down with the hooked line. This may be indicated by hook damage, often in the bill, or in the arm wing, in combination with good body condition, but e.g. fresh blood in lungs and burst internal veins.

\section{GUT = various internal problems}

This acronym is used for a range of problems observed during autopsy in the internal parts of the bird. This could be serious inflammations, e.g. in the oviduct of females, or serious kidney problems (granular obstructions); malformations, etc., or combinations of such problems. In the case of heavy cancers, the more specific acronym CAN Cancer is used. In general some details will be given under dissection notes.

\section{$P L U=$ plumage}

In some cases, birds may have had problems in primary, tail or body feather moult, which has led to such poor plumage that difficulties in flying or water-proofing may be suspected causing excessive energy needs. In other cases, birds seem to suffer from problems with the down feathers, needed for insulation and additional water-proofing. Sometimes down is completely lacking, exposing bare skin immediately below the covers.

\section{OIL = oiling}

Mineral oil in plumage is likely to have caused distrupted water-proofing of plumage or toxication.

\section{EXT = other external plumage fouling}

Substances other than mineral oils, such as vegetable or animal oils, paraffins or complex chemical mixtures may affect birds in similar ways to mineral oil.

\section{ING = ingestion}

Ingestion of materials is suspected to have caused the death of the bird, e.g. excessive amounts of paraffin or palmfat-like substances, but also extreme accumulation of plastics or other litter. 


\section{STA = starvation}

The bird died slowly from starvation, but it is unknown what has caused this. It may have been prolonged food shortage, but individual problems that cannot be identified during simple autopsies may also play a role. For example one may think of some diseases, undetected injuries, invisible pollution, poisoning or whatever.

\section{UNK = unknown}

Used if we really do not have any clue as to what has caused the death of the bird, which may be the case especially in very old or heavily scavenged corpses.

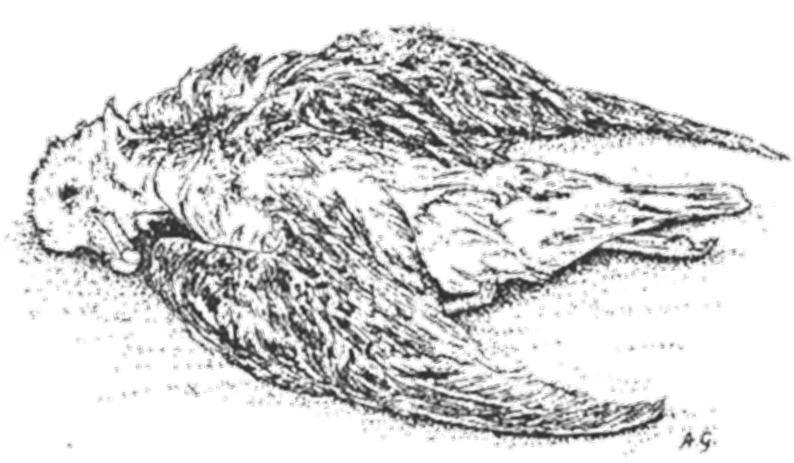

Beached fulmar

Drawing by Arnold Gronert

C2021 Wageningen Marine Research. This work is licensed under the Creative Commons CC-BY-NC-SA license. For license conditions see: https://creativecommons.org/licenses/by-nc-sa/4.0/legalcode 